\title{
Animals devoid of pulmonary system as infection models in the study of lung bacterial pathogens
}

\author{
Yamilé López Hernández ${ }^{1 *+}$, Daniel Yero ${ }^{2,3}{ }^{*+}$, Juan M. Pinos-Rodríguez ${ }^{1}$ and Isidre Gibert ${ }^{2,3}$ \\ ' Centro de Biociencias, Universidad Autónoma de San Luis Potosí, San Luis de Potosí, Mexico \\ 2 Institut de Biotecnologia i de Biomedicina, Universitat Autònoma de Barcelona, Barcelona, Spain \\ ${ }^{3}$ Departament de Genètica i de Microbiologia, Universitat Autònoma de Barcelona, Barcelona, Spain
}

\section{Edited by:}

Zsolt Molnár, University of Szeged Hungary

\section{Reviewed by:}

Paras Jain, Albert Einstein College of Medicine, New York, USA

Roman Zahorec, Comenius

University, Slovakia

*Correspondence:

Yamilé López Hernández, Centro de Biociencias, Universidad Autónoma de San Luis Potosí, Km 14.5, Carretera San Luis Potosí-Matehuala, Soledad de Graciano Sánchez, San Luis de Potosí, Mexico e-mail:yamile.lopez@uaslp.mx; Daniel Yero, Institut de Biotecnologia i de Biomedicina, Universitat Autònoma de Barcelona, Campus Universitari, Bellaterra, Barcelona 08193, Spain

e-mail: daniel.yero@uab.cat

${ }^{t}$ These authors have contributed equally to this work.
Biological disease models can be difficult and costly to develop and use on a routine basis. Particularly, in vivo lung infection models performed to study lung pathologies use to be laborious, demand a great time and commonly are associated with ethical issues. When infections in experimental animals are used, they need to be refined, defined, and validated for their intended purpose. Therefore, alternative and easy to handle models of experimental infections are still needed to test the virulence of bacterial lung pathogens. Because nonmammalian models have less ethical and cost constraints as a subjects for experimentation, in some cases would be appropriated to include these models as valuable tools to explore host-pathogen interactions. Numerous scientific data have been argued to the more extensive use of several kinds of alternative models, such as, the vertebrate zebrafish (Danio rerio), and non-vertebrate insects and nematodes (e.g., Caenorhabditis elegans) in the study of diverse infectious agents that affect humans. Here, we review the use of these vertebrate and non-vertebrate models in the study of bacterial agents, which are considered the principal causes of lung injury. Curiously none of these animals have a respiratory system as in air-breathing vertebrates, where respiration takes place in lungs. Despite this fact, with the present review we sought to provide elements in favor of the use of these alternative animal models of infection to reveal the molecular signatures of host-pathogen interactions.

Keywords: alternative model, pneumonia, zebrafish, C. elegans, Drosophila melanogaster, Galleria mellonella, tuberculosis, cystic fibrosis

\section{INTRODUCTION: A GOOD ANIMAL MODEL}

To study the pathology, host immune response and the complex interactions between host and pathogen, the use of animal models have been invaluable, but for many years, it have presented strong public, scientific concerns, as well as philosophical contradictions (Lipscomb et al., 2010). From the great contributions of Luis Pasteur and Robert Koch in the use of animal models to decipher the causal agents of several diseases, including Bacillus anthracis, Mycobacterium tuberculosis or the rabies virus, concepts related to the animal use and handle and bioethics have arise (Baumans, 2004). Russell and Burch (1959) developed the "Three Rs" principle (Replacement, Reduction, and Refinement), although their work remained largely ignored well into the 1970s (Balls and Halder, 2002). At this time, rodents were considered despicable animals and consequently they were treated without consideration, wide spreading its use as research model (Damy et al., 2010). In 1999, the Declaration of Bologna reaffirmed that "humane science is a prerequisite for good science, and is best achieved in relation to laboratory animal procedures by the vigorous promotion and application of the Three Rs" (Balls, 2009). In 2002, the genome sequence of mouse was completed (first mammal after humans; Watkins-Chow and Pavan, 2008). This fact largely contributed to the great use of mouse as animal model. However, and taken into account the principle of Replacement, several alternative models far different from the mammals classic ones, have been developed in the last years (Hendriksen, 2002).

A perfect animal model would be a model that satisfied not only scientific, but also ethical criteria (Zak and O'Reilly, 1993). Among the most controversial experimental animal models from the point of view of ethics, lung infections induced by bacteria are considered by far the most aggressive. For instance, several pathogens are able to kill non-human mammals due to lung infections. For this reason, these models need to be optimized to better reproduce human infections and acute lung damages. In addition, when an animal model is used in preclinical research, we have to consider that not all results will be successfully extrapolated from animal studies to humans (Fuchs et al., 2009; Evans et al., 2010). Some important anatomical, physiologi$\mathrm{cal}$, genetic, and molecular differences are clearly present between species.

The pathogenesis of infection is a result of the balance of the host-pathogen interaction (Mason et al., 1995). The pathogen and host genetic backgrounds are a relevant determinant of this outcome, as continuously several genes are activated or repressed depending on environmental changes during experiments. For many years it was thought that mammalian models of infection were the unique choice to study host-pathogen interactions as well as for pre-clinical evaluation of vaccines and drugs before their use in humans (Means and Aballay, 2011). However, there 
are presently numerous scientific data that have been argued to the more extensive use of several kinds of alternative infection models, such as, small vertebrates, insects, and nematodes (Kurz and Ewbank, 2007). The present review summarizes, compare and discuss the published experience in classical animal models, such as mice, and alternative animal models, particularly the zebrafish (Danio rerio), Caenorhabditis elegans and the insects Drosophila melanogaster and Galleria mellonella (the greater wax moth) in the study of bacterial agents which are considered the principal causes of lung injury.

\section{ANIMAL MODELS TO STUDY BACTERIAL LUNG PATHOGENS, SAFETY AND ETHICAL ISSUES AND THE NEED OF ALTERNATIVE METHODS \\ OVERVIEW OF MAMMALIAN MODELS FOR RESEARCH ON PULMONARY INFECTION}

The respiratory system of most non-human mammals mimics in general a lung environment in humans, in terms of chemical and physical conditions and spatial structures. In addition, the pulmonary defenses to respiratory infections in non-human mammals are somehow similar to humans. Hence, most of the pneumonia animal studies are carry out in mammals to facilitate some types of investigation (Mizgerd and Skerrett, 2008). However, extrapolation of results to humans is not straightforward owing to significant anatomical and physiological differences between species. The different mammals do not appear to present similar mucociliary clearance and alveolar macrophage morphometry (Fernandes and Vanbever, 2009).

To produce experimental pulmonary infection, mammalians offer a wide diversity of inoculation routes [reviewed and compared in Bakker-Woudenberg (2003)], being intranasal (i.n.) and intratracheal (i.t.) inoculations the infection routes seem to be the most "naturally acquired." The intratracheal model of infection requires a complex and invasive technique for disease induction but offers the advantage of allowing almost total delivery of the bacterial inoculum to the lungs. The model of infection through intranasal aspiration is the most commonly used, as it is fast and easier to perform without invasive surgical procedures and also because it mimics the natural route of infection in humans. When the inoculum is administered intranasally it could be applied as an aerosol (passive inhalation) or as nasal droplets. The intranasal aerosol model instead requires an exposure chamber with a nebulizer, and permits the simultaneous infection of several mice (Mizgerd and Skerrett, 2008). However, aerosol studies carry the greatest potential risk of infection with airborne pathogens (Chen et al., 2011), the inhaled dose varies considerably and the equipment to perform the infection is not always available in research laboratories. Most of these routes may require anesthetize animals and sometimes post-administration of pain relief drugs.

Rodents, more than other animals, are commonly used to study pneumonia. Mice are the most used in infection experiments and offer many advantages, including that they are relatively inexpensive, easy to maintain, easy to handle and their genome can be manipulate (Denny, 2005; Leung et al., 2013). Despite of this, surgical and invasive techniques are required to reproduce some acute or chronic lung diseases in mice. However, the use of general anesthesia with their side effects in host is considered as a great disadvantage of these techniques (Mizgerd and Skerrett, 2008). Guinea pigs, rats and hamsters apart of mice, are some of the other animals employed as models of lung infections (Bakker-Woudenberg, 2003).

There are well-documented relevant differences relative to lung infection between mice and humans. Differences in the structural anatomy, cellular composition of the tracheobronchial epithelium, local phagocytic and chemical defenses, inflammatory or immune response, need to be analyzed at the moment of interpreting the experimental results. Mice are different in terms of their lower complexity of the airway branches and a relatively large caliber of the airway lumen (Irvin and Bates, 2003). Furthermore, they have different cellular expression and ligand binding for selected Toll like receptors (TLRs; Mizgerd and Skerrett, 2008; Apt and Kramnik, 2009). In contrast with humans, this species has a welldeveloped broncus associated lymphoid tissues (BALTs) system, may be due to their life habits. In healthy humans, this system is practically absent (Hyde et al., 2009). However, the availability of immunological reactives as well as several mice transgenic lines has made their use almost indispensable in the majority of infection studies.

Mice are resistant (not susceptible) too many human pathogens (Lyons et al., 2004; Di Pietrantonio and Schurr, 2005; Aziz et al., 2007). Consequently, in addition to rodents, several other mammalian animal models have been explored in respiratory diseases studies: cattles, goats, sheeps, pigs, dogs, and non-human primates. The fact that non-human mammalian species are more phylogenetically related to humans justifies at least in part the use of these species by researchers. However, none of them completely reproduces all the aspects of lung diseases in humans. The most clinically relevant model has been the primate infection models, due to the high genetic and structural similarity with humans (Bem et al., 2011; Kaushal et al., 2012). Nonetheless, the cost, time, logistic and ethical considerations and the risk of zoonoses of this model mean that it can only be used in a limited fashion.

Despite the simplicity of their immune system, and their evolutionary distance to human, some non-mammalian models using small animals (fishes, nematodes, and insects) are characterized by their short generation time which redundance in the low cost of experiments. Curiously none of these animals have a respiratory system as in air-breathing vertebrates, where respiration takes place in lungs. However, such models have allowed successful screening for virulence genes in the most common bacterial lung pathogens (Table 1).

\section{ZEBRAFISH (Danio rerio) AS AN ALTERNATIVE VERTEBRATE MODEL FOR STUDYING LUNG INFECTION AGENTS}

In adult fish, respiration takes place mainly through the gills. In embryo zebrafish gill development begins by 3 days postfertilization, in the meantime cutaneous respiration accounts for nearly all gas exchange (Rombough, 2007). Naturally, zebrafish get infected by pathogens through the digestive route, the damaged fish surface or through the gills (Cantas et al., 2012). Over the past decade, several bacteria and viruses have been studied in their ability to infect zebrafish (Martin and Renshaw, 2009). 


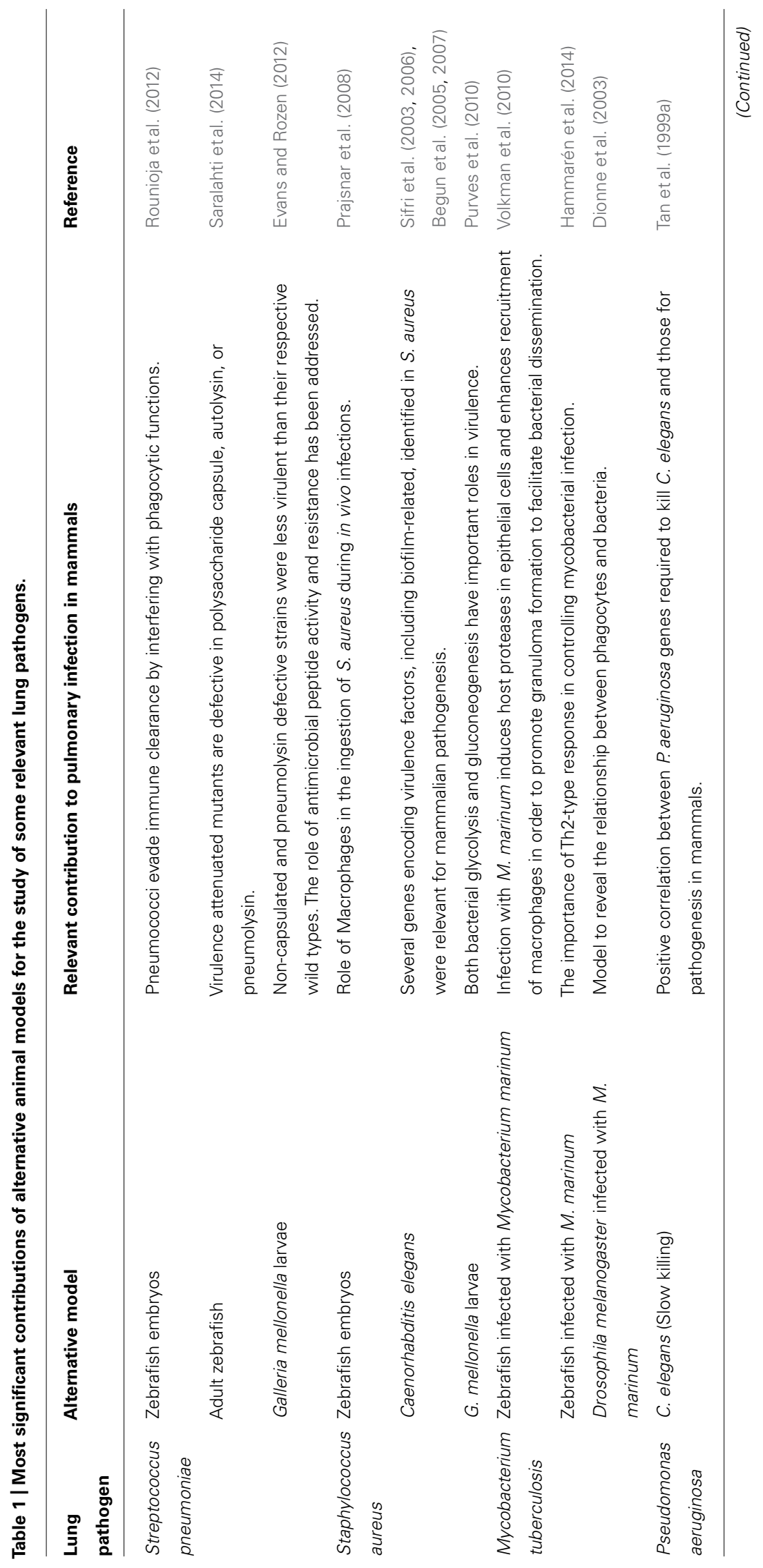




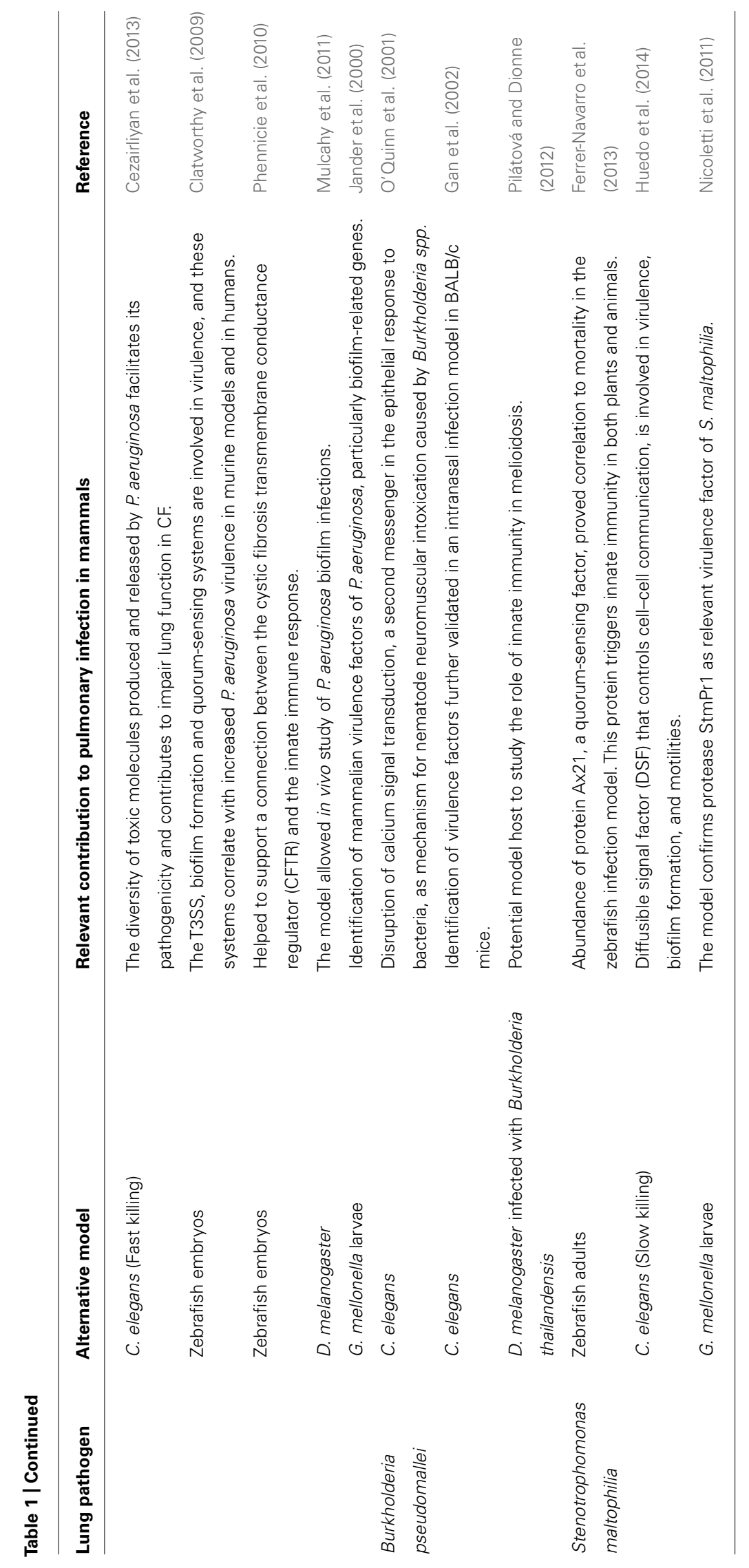


A major advantage for its use has been that during the first days after fertilization $(\approx 48 \mathrm{~h}$ until hatching) the embryos look transparent and until 3 weeks the larvae are quite translucent (Ali et al., 2011). Therefore, it is possible to follow in real time the progression of infected living embryos, using fluorescent techniques (Redd et al., 2006). However, adult fishes are gaining recognition as a model for bacterial infections because they possess a fully developed adaptive immune system (Meijer and Spaink, 2011).

The second main advantage of this model is the great possibilities that it offers for genomic and large-scale mutant analysis. Zebrafish genome is already available (Ramachandran etal., 2010) and quite well-annotated (ZF version 9; http://www.ensembl.org/Danio_rerio/Info/Index). More than 26,000 genes encoding proteins have been sequenced and annotated, showing high conservation between innate and adaptative related genes with the respective orthologs in humans (Meeker and Trede, 2008; Cui et al., 2011; Rauta et al., 2012).

Most of the mammalian immune system components and molecules have been identified in zebrafish or in other teleost species (Mitra et al., 2010; Alejo and Tafalla, 2011; Xu et al., 2012; Page et al., 2013), including a population of antigen-presenting cells very similar to the mammalian dendritic cells (Lugo-Villarino et al., 2010). Innate immunity is functional, with macrophages and neutrophils that are active at $48 \mathrm{~h}$ post-fertilization. These species have an active complement system which can be started /initiated by the same ways presents in mammals (Holland and Lambris, 2004; Sunyer et al., 2005). The adaptive immune system also consists of $\mathrm{T}$ cells and $\mathrm{B}$ cells although the main site for antigen presentation and T cell maturation is the spleen. Furthermore, multiple waves of hematopoiesis in zebrafish occur at distinct anatomical sites analogous to mammalian hematopoiesis (Kanther and Rawls, 2010).

Renshaw etal. (2007) established a model of inflammation, injuring to the zebrafish tailfin and inducing a characteristic neutrophilic inflammatory response, which resolves with a similar kinetics as in mammals. These authors defined a new model for in vivo study of inflammation resolution and their link with apoptosis (Renshaw et al., 2007). By other way, Benyumov et al. (2012) developed an in vivo zebrafish model to test phenotypic differences between human fibroblasts that participate in physiological and pathological process.

Additionally, zebrafish has been considered as replacement method for animal experiments because they present some characteristics such as high rate of fecundity, small size, easy maintenance, fast development and less stringent regulatory and ethical considerations since it has been considered that fish embryos in early developmental stages do not experiment pain, suffering, or distress. Although the ethical constraints become apparent, one study suggests that experiments with zebrafish should be subject to regulation from 5 days post-fertilization onward (Strähle et al., 2012) since is between days 5 and 6 when larvae start to feed. Thus, an animal protocol should be required to infect zebrafish older than the time the animals become free feeding. On the other hand, some recent studies say that common anesthetics are not the most "human" or humanize option for zebrafish euthanasia and could cause animal suffering (Cressey, 2014), adding evidences that it is necessary to minimize distress or death.

As in preclinical researches with mammalian models, adult animals should be allocated for several days under special conditions before beginning the experimental procedures, in order to reach their adaptation to new laboratory conditions and to recover from stress (Figure 1). When zebrafish embryos are used, this time is relatively short because they develop very rapidly. To reach a pathogenic dose, as for traditional infection in mice models, zebrafish infection involves a single dose of bacteria requiring an initial population of pathogens able to proliferate avoiding, long enough, the detection by immune cells. However, when adult fish are less susceptible hosts for bacterial infection, higher amount of live bacteria are required when compared to infection in mice. For instance, intraperitoneal infection of zebrafish with the

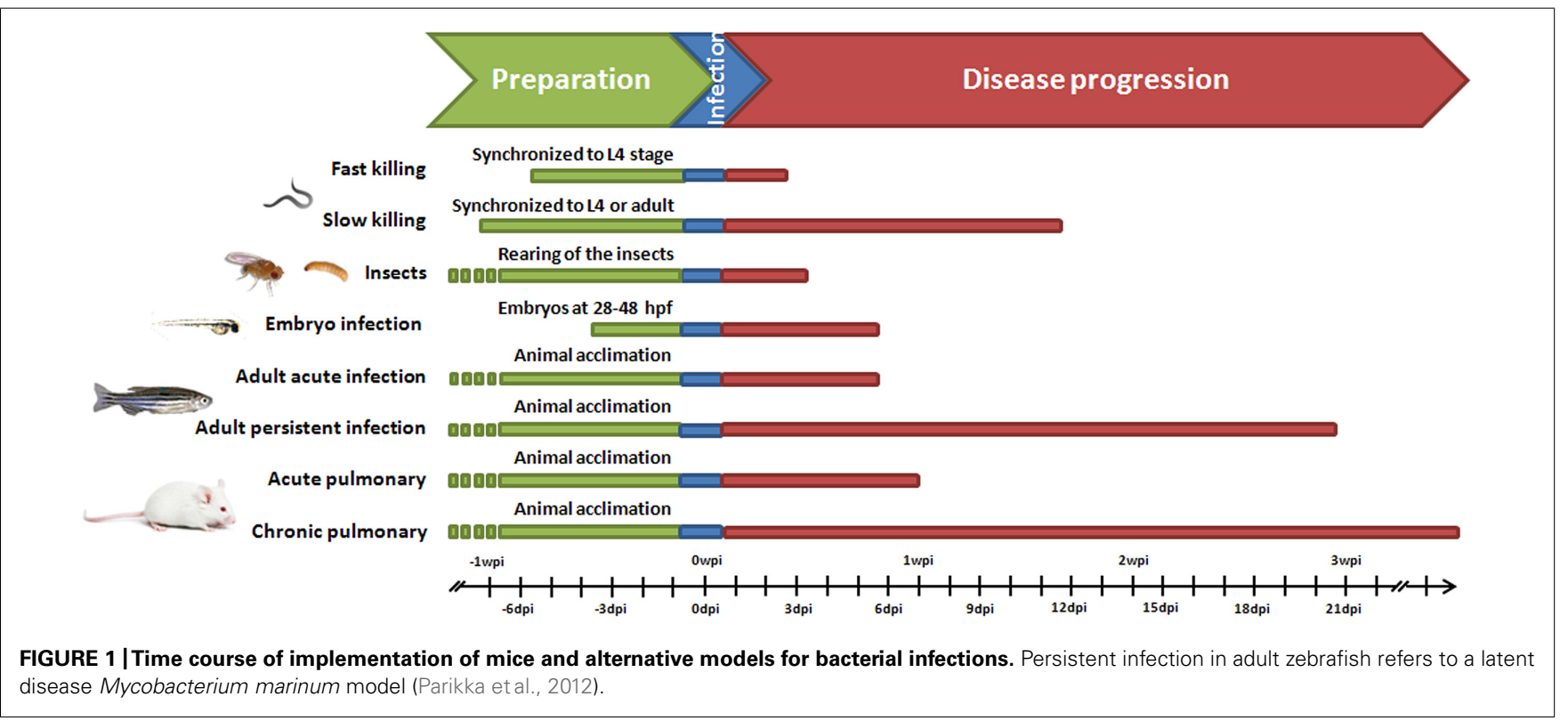


Pseudomonas aeruginosa PAO1 strain or with Stenotrophomonas maltophilia clinical isolates reported median lethal dose $\left(\mathrm{LD}_{50}\right)$ values of approximately $5 \times 10^{7} \mathrm{cfu} /$ dose or $5 \times 10^{8} \mathrm{cfu} /$ dose respectively (Ferrer-Navarro et al., 2013; Huedo et al., 2014; Ruyra et al., 2014). Infection models in zebrafish usually are conducted within the time frame of days rather than weeks to months (Figure 1), but in the adult persistent mycobacterial infection model a timeline of progression of infection could reach to weeks post-infection (Cronan and Tobin, 2014; Hammarén et al., 2014). Also in zebrafish embryos and larvae, $P$. aeruginosa requires higher dose of pathogens to establish a virulent infection because many of these pathogens are killed by macrophages and neutrophils (Brannon et al., 2009).

\section{Caenorhabditis elegans AS A NON-VERTEBRATE MODEL FOR STUDYING OF LUNG BACTERIAL AGENTS}

In 1963 Sydney Brenner proposed the nematode C. elegans as an experimental organism for pursuing research in developmental biology and neurology (Ankeny, 2001). C. elegans has fewer than 1000 body cells when completely grown. C. elegans possesses remarkable advantages that make it an ideal model, for example, low cost, simple growth conditions, and a short generation time with an invariant cell lineage. By other way, at present, there are many molecular and genetic methods for its manipulation (Kurz and Ewbank, 2000). The genome of C. elegans was completely sequenced at the end of 1998 (Schulenburg and Ewbank, 2007). In comparison with mice, is obvious that culture and maintenance of C. elegans is far simpler and cheaper. Besides, ethical regulations are practically absent for experimentation with worms. Regarding to cell cultures, C. elegans contaminated stocks are easily identified and cleaned better than mammalian contaminated cells (Hulme and Whitesides, 2011).

Fascinatingly, this worm shares similarity to mammalian immune system, particularly signaling cascades in innate immunity in response to pathogen invasion (Alper et al., 2008). Because nematodes consume microorganisms as their food source, there is presumably selection pressure to evolve and maintain immune defense mechanisms (Kim et al., 2002; Alper et al., 2010; Shivers et al., 2010). While the human lung and the nematode intestine clearly differ in several anatomical, cellular and biochemical characteristics, in the nematode intestine it is possible to identify pathogen-specific virulence factors that interact with epithelial surfaces. To reinforce the wide field of applications of such nonvertebrate models, the study carried out by Green et al. (2009) describe, despite of the absence of lungs in the nematode, a practical model to evaluate the impact of the cigarette smoke exposure on innate immunity. In this study, C. elegans responded to nicotine, which is one of the main components of cigarette smoke, converting nicotine to cotinine, in a similar manner to mammals and opening the path to demonstrate that the animals are absorbing the smoke. In this model, C. elegans was subjected to whole cigarette smoke exposure, overcoming several aspects impossible to elucidate using human epithelial cell lines, showing down-regulation in many genes in response to the smoke, mainly several host defense genes (Green et al., 2009).

Additional advantage of using nematodes as animal model of bacterial infection lies in reduced experimental time without the need of animal acclimation before infection, and time-kill curves taking only few hours (fast killing) or days (slow killing) post-infection depending on the killing mechanism (Figure 1). However, nematodes need to be synchronized about 1 week prior to infection to reduce the variation in results associated to differences of age. There are two methods to synchronize worms: egg preparation via bleaching and egg lay (Sulston and Hodgkin, 1988). The first method produces more progeny than the latter; however, egg lay can generate a better synchronized population. Scientists take also advantage of temperature-sensitive sterile $C$. elegans mutants (e.g., the CF512 strain) to avoid production of a brood that would complicate the scoring of death of the infected worms. These animals do not produce progeny at working temperature $\left(25^{\circ} \mathrm{C}\right)$, thus simplifying the procedure. However, these strains appear to be slightly more resistant to bacterial infections (Feinbaum et al., 2012).

More than 40 human pathogens, or their close relatives, are known to cause disease in C. elegans (Sifri et al., 2005). P. aeruginosa was the first broad host-range pathogen, able to kill $C$. elegans (Tan et al., 1999a,b). C. elegans infection process has the advantage to closely resemble chronic infection, because the host is usually exposed to maximal dose of pathogen. On the other hand, among killing mechanisms, slow killing involves a process similar to those related to an infection process. At present, there are five distinctive mechanisms of worm killing identified: infection with intestinal colonization, persistent infection, invasion, biofilm formation, and toxin-mediated killing (Smith et al., 2002; Beale et al., 2006; Dunbar et al., 2012). Obviously, in the C. elegans model will be possible to study only those human diseases caused by pathogens able to infect the nematodes. In addition to the bacterial species, the killing mechanism is in most cases dependant to the way the bacterium is prepared prior to infection. For instance, depending on the composition of the agar medium where the bacterium is grown, the rate of $P$. aeruginosa-mediated killing of $C$. elegans will be different (Tan etal., 1999a). If the P. aeruginosa tested strain is grown on minimal medium, the killing will occur in the course of several days; by the contrary, if a high-osmolarity medium is used, the killing will occur in the course of several hours.

\section{INSECT AS MODELS OF INFECTION}

In opposite to mammals, the respiration process in insects occurs by a network of tubes called tracheae and tracheoles. Despite this, insects have recently been shown to be a valuable alternative to animal models for bacterial pathogenesis studies. This is mainly due to the fact that insects have a relatively advanced system of antimicrobial defenses. Like mammals, insects possess a complex innate immune system and display evolutionary conservation of signaling cascades (Lemaitre and Hoffmann, 2007). In addition, as with other non-vertebrate models, the advantages are the low cost of maintenance and no ethical concerns. There are multiple genetic and molecular tools available. By other way, these models have a precise endpoint. The low cost of maintenance and the rapid development, allow their use in high animal number for proper statistical analysis of results. Among these models, the common fruit fly $D$. melanogaster and the larvae of $G$. mellonella, have been 
shown to be relevant for several fungal and bacterial mammalian pathogens (Limmer et al., 2011; Sprynski et al., 2014).

Most insects have a very rapid life cycle, which consists of four clearly defined stages: the embryo, the larva, the pupa, and the adult. In addition, insect rearing is easy and relatively cheap (Ramarao et al., 2012). For larva, drugs can be administered directly injecting the organism or mixing with media (solid or liquid with $2 \%$ yeast paste). For adults, drugs may be delivered as aerosol, mixed with food, injected or applied directly to the nerve cord. In the injection method, a needle or a nanoinjector preloaded with pathogen culture is used to prick the body cavity (insect hemocoel). Injection requires anesthetization, which is usually done with carbon dioxide, and requires the transfer of insects into vials containing food, where the worms incubated at $25-30^{\circ} \mathrm{C}$ and their survival is evaluated (Igboin et al., 2012). For ingestion, it is common to introduce the insects into small laboratory tubes containing filter disks embedded with media containing pathogens of interest.

Galleria mellonella larvae are cost effective, widely available and the results can be obtained within 2 or 3 days (Figure 1). There are three main ways in which Galleria fight bacterial infections: circulating phagocytic hemocytes that patrol the hemolymph; proteolytic cascades that can be quickly triggered, activating the melanization response and inducing antimicrobial immune effectors such as lysozymes, as well as antimicrobial peptides which can be rapidly synthesized by the fat body (Yuen and Ausubel, 2014). An added benefit of using Galleria for pathogenesis studies is that infections can be carried out at $37^{\circ} \mathrm{C}$ or higher, as Galleria tolerates relatively high temperatures, unlike the Zebrafish, $D$. melanogaster and C. elegans (maximum 25-28 ${ }^{\circ}$ C; Glavis-Bloom et al., 2012). The larger size of the Galleria larva, compared to other invertebrate models, also allows it to be infected with larger and more controlled doses of the pathogen without significantly traumatizing the insect. Some disadvantages of the G. mellonella model rely in the fact that genetic methods for generating recombinant organisms and to sequence them are not completely available. However, this model could be improved in the next years and hopefully, could be used for more pathogens, for which no alternative models of infection exist.

\section{FROM CLASSIC TO ALTERNATIVE MODELS IN STUDYING RELEVANT BACTERIAL LUNG PATHOGENS}

The most common causes of bacterial lung infections in normal human hosts include Streptococcus pneumoniae, Haemophilus influenzae and Staphylococcus aureus, and the recent increase of M. tuberculosis. Pneumonia is classified according the source of infection into community-acquired pneumonia (CAP), hospitalacquired or nosocomial, aspiration of foreign material and immunocompromised host (Woodhead, 2013). In basis of their presentation, pathogens have been classified into "typical" and "atypical." Typical organisms in CAP include S. pneumoniae, H. influenzae, S. aureus, Moraxella catarrhalis, and P. aeruginosa (Musher and Thorner, 2014). Atypical organisms include Legionella species, Mycoplasma pneumoniae, Burkholderia spp., Chlamydia spp., Chlamydophila spp., Coxiella burnetii and viruses (Jones, 2010). In almost all epidemiological studies of hospitalacquired pneumonia (Jones, 2010; Barbier et al., 2013; Polverino et al., 2013; Erdem et al., 2014), a consistent six organism groups (S. aureus, P. aeruginosa, Klebsiella species, Escherichia coli, Acinetobacter species, and Enterobacter species) caused $\sim 80 \%$ of episodes, with lower prevalences of Serratia species, S. maltophilia, and community-acquired pathogens, such as pneumococci and $H$. influenzae. In compromised hosts, the bacterial causes of pneumonia are much broader, including species not usually considered of high virulence in humans. For instance, Mycobacterium sp., Burkholderia spp., P. aeruginosa, and S. aureus are the most important infectious agents in cystic fibrosis (CF) patients (Coutinho et al., 2008).

For the most frequent bacteria causing pneumonia, scientists have developed animal models of infection, mainly using mice (Figure 2 and Table 1). However, the introduction of alternative non-mammalian models is still at its beginning and obviously for host-permissive pathogens the contribution would be higher. For instance, despite several mouse M. tuberculosis lung infection models are utilized, and Mycobacterium marinum infection of fishes results in chronic granulomatous diseases similar to mycobacterioses in mammals (Cosma et al., 2006b), C. elegans, a well-established model host, is resistant to mycobacterial infection (Couillault and Ewbank, 2002). The most extreme example is that of pathogens for which there are no or very few alternative models of infection, such as $H$. influenzae, $M$. catarrhalis, and M. pneumoniae (Figure 2). On the other side as will be discussed later, $P$. aeruginosa, a versatile and ubiquitous bacterium, is capable to survival and colonize various living host organisms facilitating the development of infection models spanning from nematodes to small vertebrates (Figure 2). Here, we discuss the models that have been developed for studying most common human lung pathogens by comparing the mouse model with alternative ones in zebrafish, nematodes, and insects.

\section{ANIMAL MODELS OF PNEUMOCOCCAL INFECTION}

Streptococcus pneumoniae is considered the most common bacterial agent in CAP and a great number of animal models of pneumococcal diseases are available. Some review articles from the past decade have specifically mentioned the value of animal models to test pneumococcal vaccines (Briles et al., 2000; Adamou et al., 2001; Bogaert et al., 2004; Kadioglu and Andrew, 2004; Morsczeck et al., 2008) and the use of murine models of pneumonia to evaluate protein-mediated antimicrobial responses (Srivastava et al., 2007), the mouse genetic susceptibility to pneumococcal disease (Proft and Fraser, 2003) and for investigating the pathophysiology of bacterial meningitis (Teles et al., 1997; Gerber et al., 2001; Blair et al., 2005; Endo et al., 2012).

On the other hand, as there are several evidences about the positive correlation between infection with Streptococcus iniae and Streptococcus pyogenes in zebrafish and mammalian models, there is simple to assume the use of zebrafish to evaluate host-pathogen interactions during pneumococcal infection (Borst et al., 2013). In a recent work, Rounioja et al. (2012) reported the use of zebrafish embryo to evaluate the response of the host immune system against challenge with pneumococci. They also reported that this response is dependent on whether the pneumococci could evade clearance by interfering with host phagocytic 


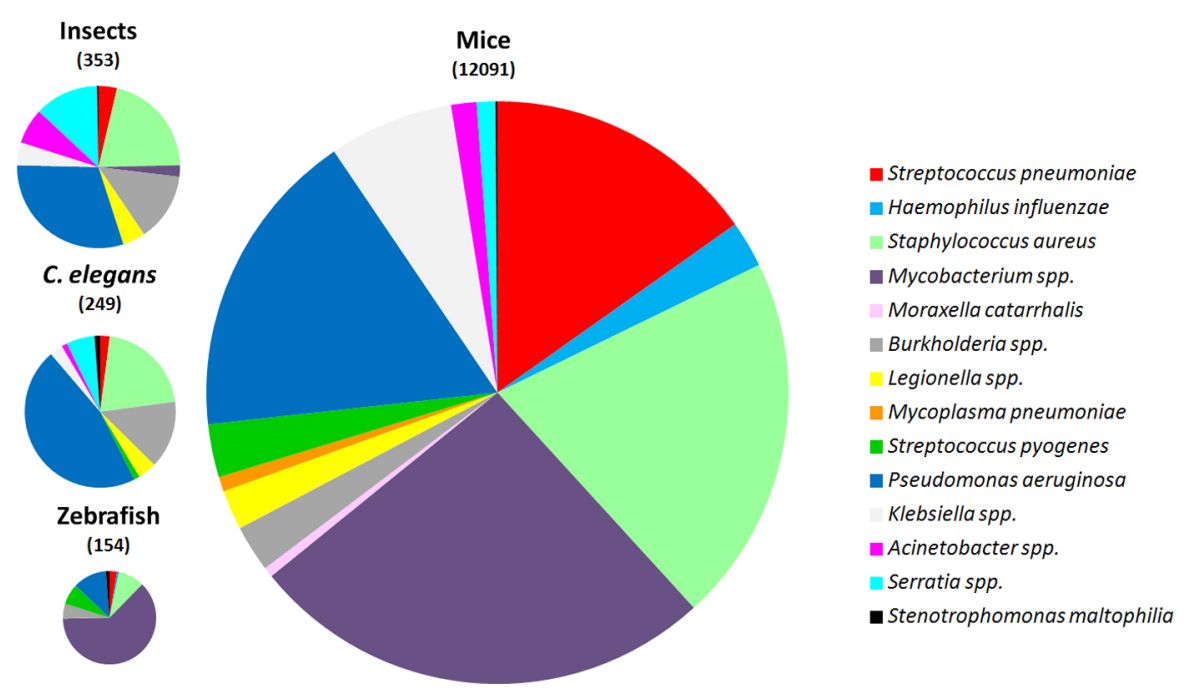

FIGURE 2 | Comparative number of publications for different lung pathogens employing mice, Caenorhabditis elegans, zebrafish, and insects as animal models of infection. The number of publications is shown between parentheses. A systematic search was conducted using PubMed (http://www.ncbi.nlm.nih.gov/pubmed). Literature searches were conducted to identify studies published until 1 November, 2014. function. Moreover, pneumococcal mutants defective in important virulence factors were attenuated in this in vivo model system (Rounioja et al., 2012). The adult zebrafish model can be also used to investigate pneumococcal diseases (Saralahti et al., 2014). The authors showed that $S$. pneumoniae mutants defective in polysaccharide capsule are also attenuated and that elimination of pneumococci depends mainly on host innate immune responses.

To our knowledge, little is the information available up to day related to the use of $C$. elegans to study pathogenesis of Streptococcus. Garsin et al. (2001, 2003), in two separate works, demonstrated the suitability of using $C$. elegans as a model host for Gram-positive infection, including Enterococcus faecalis, $S$. aureus, and S. pneumoniae. Jansen et al. (2002) demonstrated that S. pyogenes kills C. elegans, both on solid and in liquid medium, mediated by the hydrogen peroxide production (Jansen et al., 2002; Bolm et al., 2004).

The potential application of the larvae of G. mellonella as an informative infection model for $S$. pneumoniae has been also studied (Evans and Rozen, 2012) since strains differing in known virulence factors could be distinguished in this host. Strains lacking capsule or pneumolysin showed less virulence than their respective wild types. Particularly, pneumolysin plays a role in damaging human lung epithelium, allowing the establishment of infection (Rayner et al., 1995).

\section{ANIMAL MODELS OF STAPHYLOCOCCAL INFECTION}

As nasal colonization is a main requisite for the establishment of S. aureus infection in humans (Baur et al., 2014), mice infected by using this route is a useful model for characterizing early host responses. However, this model has failed in mimic the whole natural route of infection, resulting in self-limited disease (Alami et al., 1968; Bartell et al., 1968; Anatolǐ et al., 1971; Ansfield etal., 1977; Bragonzi etal., 2004; Bloemendaal etal.,
2011). The Bolus infection models, where mice are challenged by i.t. and i.n. inoculation have been more successful in producing intrapulmonary infection and host mortality (Jakab, 1976; Hu et al., 2006; Rajagopalan et al., 2006; Huzella et al., 2009; Fernandez et al., 2011; Park et al., 2011). Sawai et al. (1997) described a murine model of acute staphylococcal pneumonia inoculating mice by intravenous (i.v.) injection of a suspension containing bacteria enmeshed in agar-beads. This model allows the bacteria to remain in the lung for several weeks, and it is reproducible and simple (Sawai et al., 1997).

$\mathrm{Li}$ and $\mathrm{Hu}$ (2012) developed a zebrafish embryo infection model with $S$. aureus at $36 \mathrm{~h}$ post-fertilization. These researches inoculated the bacteria directly into the pericardial cavity, eye, and yolk body. By using GFP-expressing S. aureus and transgenic zebrafish lines along with multicolored confocal fluorescence methods, they could analyze different phases of bacterial infection. As important conclusion from this work, the dynamic of infection clearly depends on the bacterial entry routes ( $\mathrm{Li}$ and $\mathrm{Hu}, 2012$ ). Prajsnar et al. (2008), using a similar model, identified staphylococcal virulence genes, whose respective mutants are attenuated in zebrafish. The virulence factors include a peroxide regulon repressor, a protein involved in starvation survival and a response regulator involved in controlling exoproteins production. They also demonstrated that in zebrafish embryos, macrophages phagocytize $S$. aureus during in vivo infections. Accordingly to Kubica et al. (2008), these immune cells act as a reservoir during infection. This model in both zebrafish embryos and adults also allowed rapid screening of mutants for those strains with attenuated pathogenicity, identifying relevant factors of pathogen virulence and host immunity (Lin et al., 2007; Li and Hu, 2012; Lü et al., 2012).

On the other hand, several studies used the C. elegans model to assess virulence levels between some different methicillinresistant $S$. aureus strains, demonstrating the suitability of this 
model for studying the virulence and pathogenicity of $S$. aureus strains (Wu et al., 2010, 2012, 2013). In addition, several S. aureus virulence determinants recognized as important in mammalian pathogenesis are also identified as relevant for full pathogenicity in nematodes, including agr (a quorum-sensing global virulence regulatory system), sarA (global virulence regulator), the alternative sigma factor $\mathrm{B}$, alpha-hemolysin, and V8 serine protease (Sifri et al., 2003, 2006). However, Polakowska et al. (2012) showed that there is no substantial variation in virulence among different staphylococcal strains using this experimental model, questioning the usefulness of it.

In another work, JebaMercy et al. (2011) performed solid and liquid assays for the infection of C. elegans with S. aureus, demonstrating that $S$. aureus took $\sim 90 \mathrm{~h}$ for the complete killing of $C$. elegans and thereby postulating that colonization with live bacteria was necessary for worm killing. Using an interactive genetic approach, Begun et al. (2007) established a novel in vivo experimental model to explain the interaction between the bacteria biofilm matrix and components of the innate immune system. This study demonstrates the ancient conserved function against predation linked to the protective activity of biofilms. In another work based on C. elegans infections, the same authors identified staphylococcal genes relevant for mammalian pathogenesis, including the product of the nagD gene, which was not previously described as a virulence factor (Begun et al., 2005).

Larvae of the greater wax moth also have provide insights into the pathogenesis of $S$. aureus, principally as a suitable host for testing the in vivo efficacy of antimicrobial agents (Gao et al., 2010; Desbois and Coote, 2011; Gibreel and Upton, 2013; Apolónio et al., 2014). In addition, using this models authors have demonstrated for the first time that both glycolysis and gluconeogenesis have important roles in virulence (Purves et al., 2010). Their results showed that two glyceraldehyde-3-phosphate dehydrogenase (GAPDH) homologs (GapA and GapB) are required for the virulent phenotype of $S$. aureus in this model. In $S$. pyogenes surface-associated GAPDH was associated with antiphagocytic properties and host cell adherence (Boël et al., 2005).

\section{ANIMAL MODELS FOR MYCOBACTERIAL PATHOGENESIS}

Due to the complex interaction between the pathogen and the host, it has been very difficult to find out an ideal model to study mycobacterial pathogenesis. Some mice strains can be easily infected via aerosol with a low dose of M. tuberculosis, multiplying in the lungs and subsequently spreading to liver and spleen. The infection is controlled but not eliminated, by cell-mediated immunity, mainly $\mathrm{T}$ cell responses, and the infection is well-tolerated for more than 1 year (Beamer and Turner, 2005; Aguilar et al., 2007, 2010; Andreevskaia et al., 2007). Hence, the mouse model has been largely a suitable infection model (Orme, 2005b; Cooper, 2014). Surprisingly, there is still no ideal and validated model of experimental tuberculosis disease (Vilaplana and Cardona, 2014), and the mechanisms leading to latency and reactivation of are still unclear (Parikka et al., 2012).

BALB/C mice infection models by i.t. injection using a high dose of bacilli (Hernández-Pando et al., 1996) is one of the most employed models. This model has greatly contributed to elucidate the role of antibodies in the protection against mycobacterial infections (López et al., 2009, 2010; Alvarez et al., 2013), and to the screening and validation of new vaccine candidates (CastilloRodal et al., 2006; López et al., 2006). Alternatively, C57BL mice have been infected i.n. via aerosol with a low dose of $M$. tuberculosis, which produces a well-tolerated infection dominated by Th1 response (Kelly et al., 1996; Cardona et al., 2003; Aldwell etal., 2005; Saini etal., 2012). For this reason, this is actually a model of slow progressive disease, and the animal death is produced by excessive inflammation or immunopathology (Mustafa et al., 1999a,b, 2000). The model of latent tuberculosis has been also partially reproduced experimentally in mice (Phyu et al., 1998; Shi et al., 2011; Zhang et al., 2011) which are injected intratracheally with relatively low numbers of the virulent strain H37Rv (Hernandez-Pando et al., 1998). After that, low and stable bacillary counts with few granulomas appear and the mice continue gaining weight and appear healthy for more than 2 years.

Although mice are the most employed animal model for studying human TB, it has important drawbacks. Due to the fact that M. tuberculosis is not a natural pathogen of mice, the pathological development of TB will be clearly different from that in human. As relevant characteristic, we can mention the absence of granulomas formation in lungs from mice (Grumbach et al., 1967; Karakousis et al., 2004; Mollenkopf et al., 2004; Orme, 2005a,b; Hunter et al., 2007; Dharmadhikari and Nardell, 2008; Young, 2009; Apt, 2011). The immune response elicited in mice after mycobacterial infection is able to control bacillary load even without causing marked lesions (Vilaplana and Cardona, 2014). Therefore, mice are generally resistant to TB infection when compared with other rodents, and even humans, as evidenced by their ability to tolerate relatively large bacterial numbers within their lungs without signs of disease (Be et al., 2008; Dharmadhikari and Nardell, 2008; De Steenwinkel et al., 2009). Also, ethically, these models in conjunct appear to be more aggressive to the mice.

Zebrafish and fruit fly are emerging as alternative models and have provided new insights into the pathogenesis of the tuberculosis disease. By the contrary, C. elegans, to our knowledge, seems to be not a feasible model for infection with $M$. tuberculosis. The zebrafish has been a key model in our understanding of mycobacterial infection. Studies on this model employ a fish pathogen, M. marinum, a close relative to M. tuberculosis (Tobin and Ramakrishnan, 2008). This bacterium is a natural pathogen of fish and amphibian (van der Sar et al., 2004a,b). The M. marinum infection produced in these hosts is quite similar to those produced in humans, mainly in the granuloma formation (Prouty et al., 2003; Berg and Ramakrishnan, 2012). Low doses ( $<100$ bacteria) of M. marinum lead to a chronic infection in adult zebrafish (Parikka et al., 2012), while higher doses cause a fatal acute infection (Cosma et al., 2006b). Besides, M. marinum grows faster than $M$. tuberculosis, it can be easily manipulated and requires only common laboratory precautions (biosafety level 2). The zebrafish/M. marinum infection model changed the old conception that granuloma formation requires lymphocytes and by the contrary, postulated that the granuloma actually functions as a bacterial tool for disseminating the disease.

Experiments conducted by Ramakrishnan and colleagues using the zebrafish/M. marinum infection model (Davis et al., 2002; 
Davis and Ramakrishnan, 2009; Ramakrishnan, 2013), demonstrated for the first time new mechanisms of bacterial dissemination: the bacterial transfer between two macrophages through membrane tethers and re-phagocytosis of bacteria associated with dead macrophages in tissues. They also observed that, as early as $72 \mathrm{~h}$ post-injection, the extravasated infected macrophages began to form granuloma-like aggregates in the tissues, establishing that there is not needed the participation of adaptive immunity to initiate granuloma formation (Davis et al., 2002). Using this model, and taking advantages of the powerful live imaging of the zebrafish model, it was determined that an efficient bacterial expansion depends on the mycobacterial region of deletion 1 (RD1) locus. The researchers also demonstrated that the bacterial protein ESAT6 elicits the expression of metalloproteinase 9 (MMP9) in the host, and both proteins act together for granuloma formation (Pozos et al., 2004; Volkman et al., 2004; Cosma et al., 2006a; Berg and Ramakrishnan, 2012; Takaki et al., 2013; Cambier et al., 2014). These findings showed that one protein from the host and one from the bacteria, constitute a virulence axis which evade the host's early immune responses and lead to mycobacterial dissemination. This study is, from our point of view, the most important evidence of how the zebrafish model can be used to validate and to re-postulate host-pathogen interactions during mycobacterial infection.

On the other hand, Swaim et al. (2006) reported that lymphocytes play the same critical role in controlling mycobacterial infection in fishes and mammals by the use of a defective zebrafish mutant in the ragl gene. They also demonstrated that bacteria defective in RD1 region are also attenuated in zebrafish. In addition, the zebrafish/M. marinum model has proven to be useful for studying the latency, dormancy, and reactivation of latent or subclinical tuberculosis (Parikka et al., 2012). This group has recently studied using this model the $\mathrm{T}$ cell responses in mycobacterial infection and they have found associations between the disease severity (bacterial load) and the type and magnitude of $\mathrm{T}$ cell responses, particularly an adequate Th2-type response (Hammarén et al., 2014). This infection model also helped to demonstrate that mycobacterial antigens Ag85B, CFP-10, and ESAT-6 protect adult zebrafish from mycobacterial infection (Oksanen et al., 2013), paving a new way in tuberculosis vaccine research.

Mycobacterium marinum also causes a lethal infection in the fly $D$. melanogaster characterized by a widespread tissue damage, even at significant low bacterial doses (Dionne et al., 2003). These initial stages of the infection were very similar to the early stages in frogs and fishes infected with M. marinum (Pozos et al., 2004). This model may be valuable in testing the activity of new antimycobacterial agents (Oh et al., 2013).

\section{ANIMAL MODELS TO STUDY THE VIRULENCE FACTORS OF Pseudomonas aeruginosa}

Pseudomonas aeruginosa is an opportunistic human pathogen that can also infect several diverse organisms, such as plants, nematodes, insects, and mammals. Thus, we counted on good mammalian and non-mammalian models for studying virulence factors of $P$. aeruginosa. In humans, $P$. aeruginosa is widely associated with nosocomial infections in CF patients (Moreau-Marquis et al., 2008) and other immunocompromised individuals, and the resolution of the infections is hampered due to the formation of drug resistance biofilms. Until the moment, a difficult exists on studying biofilms formation in the context of animal and human lungs. However, several non-mammalian models have provided compelling data regarding $P$. aeruginosa biofilm formation (reviewed in Lebeaux et al., 2013).

Acute and chronic models of lung $P$. aeruginosa infection have been developed using several mammalian species (rats, guinea pigs, hamsters, mice, sheep, rabbits, and baboons; Seidenfeld et al., 1986; Starke et al., 1987; Pier et al., 1990; Collins et al., 1991; Iwata and Sato, 1991; Hart et al., 1993; Terashima et al., 1995; Bakker-Woudenberg et al., 2002; Luna et al., 2007, 2009; Kurahashi et al., 2009; Rodríguez-Rojas et al., 2009; Collie et al., 2013). The chronic infection model has been extensively used and characterized, showing certain similarities with human pathology due to the persistence of the inoculum and the resultant lung pathology (van Heeckeren and Schluchter, 2002). Depending on the route, dose administered, and the frequency of dosing, acute lung infection with either rapid clearance of the bacteria or acute sepsis and death could take place (George et al., 1991). Using this model, it has been shown that $P$. aeruginosa must express several key virulence factors (Balloy et al., 2007).

A literature survey about acute vs. chronic P. aeruginosa lung infections clearly shows that to induce an infection for more than 1 month, it is necessary to use an immobilizing agent such as agar, agarose, or seaweed alginate together with the bacterial suspension (Iwata and Sato, 1991; Hart et al., 1993; McMorran et al., 2001; Moser et al., 2002). The initial agar-beads model of chronic pulmonary infection with $P$. aeruginosa was modified for its use in mice by Starke et al. (1987) and has been widely used to study CF lung disease, bacterial pathogenesis (Gosselin et al., 1995, 1998; Morissette et al., 1995; Stevenson et al., 1995; Moser et al., 1997; Sapru et al., 1999; Tam et al., 1999; McMorran et al., 2001), and for the evaluation of new therapies (Pier et al., 1990; Staczek et al., 1998; Chmiel et al., 1999; Wilmott et al., 2000) and virulence factors (Rodríguez-Rojas et al., 2009). Researchers have also developed a mouse model with a lung pathology similar to human CF. One group generated mice that absorb excess sodium in the airways (Mall et al., 2004; Mall, 2008) and these animals developed airway obstruction with dehydrated mucus. This CF model promises to answer important questions about the cause of the inflammation that leads to lung damage and failure in CF (Mall et al., 2004; Mall, 2008). Both acute and chronic models require extensive use of animals and labor-exhausting techniques to prepare and immobilizing bacteria in agar, as well as good surgery skills.

Brannon et al. (2009) developed a zebrafish embryo infection model for the study of systemic $P$. aeruginosa infection, and for evaluating the virulence of a type 3 secretion system (T3SS) mutant. By fluorescence microscopy it was possible to follow in real time $P$. aeruginosa infection in transgenic zebrafish with fluorescently labeled neutrophils and macrophages (Hall et al., 2007). Clatworthy etal. (2009) demonstrated that lethal infection requires quorum-sensing and the T3SS for full virulence in late-stage zebrafish embryos infected with $P$. aeruginosa. Curiously, T3SS expression has been associated also to increased risk 
of $P$. aeruginosa infection in hospitalized patients (Ledizet et al., 2012) and it is also associated with initial infections in patients with CF (Jain et al., 2008). They demonstrated that the infection outcome could be influenced on the pathogen side, by both the inoculum size and the presence of known virulence determinants (lasR, $m v f \mathrm{R}$, and $p s c \mathrm{D}$ ) and on the host side by developmental stage and the modulation of the immune system (Clatworthy et al., 2009). They also showed that the infection process can be modified through the use of morpholinos or antibiotics, which were used to shift immune cell numbers or rescue embryos from lethal challenge respectively.

In one study performed by Phennicie et al. (2010) in zebrafish, the role of the cystic fibrosis transmembrane conductance regulator (CFTR) in the innate immune response to acute infection with $P$. aeruginosa was evaluated. The authors found that the $P$. aeruginosa bacterial load was significantly higher in $c f t r$ morphants (knockdown of the zebrafish ortholog to human cftr) than in control embryos, according with similar studies performed with mice and human bronchial epithelial cells.

The $P$. aeruginosa-zebrafish infection model has allowed conducting chemical screens for small molecules or antimicrobial compounds. For instance, the treatment of infected embryos with front line antipseudomonal agents could save zebrafish embryos from a lethal $P$. aeruginosa challenge (Clatworthy et al., 2009). More recently, Ruyra etal. (2014) reported the use of immunostimulant-loaded nanoliposomes to protect adult fishes against bacterial or viral infections. In a model of adult zebrafish infection developed by these researchers, nanoliposomes protected zebrafish against otherwise lethal bacterial ( $P$. aeruginosa PAO1) and viral (SprinViraemia of Carp Virus) infections.

Tan et al. (1999a, 1999b) conducted several studies (Tan and Ausubel, 2000; Tan, 2002) showing for the first time the use of $C$. elegans in the study of $P$. aeruginosa pathogenesis. They demonstrated that accumulation of $P$. aeruginosa cells in intestines is crucial to explain the killing mechanism. In addition, as other authors have demonstrated, they showed that bacterial genes required for this killing were also described in mammalian or plant hosts pathogenesis. Feinbaum et al. (2012) screened mutants with reduced ability to kill C. elegans using a mutant library representing $\sim 80 \%$ of the non-essential $P$. aeruginosa PA14 genes. They described a set of $180 P$. aeruginosa genes necessary for normal levels of virulence. The principal contributors to $P$. aeruginosa virulence in the $C$. elegans infection model were genes that play key roles in survival of $P$. aeruginosa within the host intestine, particularly regulatory genes that are involved in quorum-sensing (Feinbaum et al., 2012).

Insects have been also surrogate model systems for identifying mammalian virulence factors of $P$. aeruginosa. Previous studies showed that this bacterium is a virulent pathogen of fruit flies (Boman et al., 1972). Using the D. melanogaster as model host, D'Argenio et al. (2001) have identified mutants of P. aeruginosa with reduced virulence. Among these mutants, the pil-chp signal transduction system is particularly relevant also in mammals and is involved in type IV pilus synthesis and biofilm formation (Kato et al., 2008). The D. melanogaster model allowed in vivo study of $P$. aeruginosa biofilm infections by oral administration (Mulcahy et al., 2011). By the other hand, several studies summarized by
Jander et al. (2000) point out similarities between virulence of $P$. aeruginosa mutants in mice and G. mellonella. This infection model helped to demonstrate that human anti-microbial peptides that inhibited the initial steps in biofilm formation could be used in the development of new therapies for $P$. aeruginosa infection (Dean et al., 2011).

\section{ALTERNATIVE MODELS FOR TWO LESS COMMON BACTERIAL LUNG PATHOGENS}

Previous works suggest a limited invasiveness of Stenotrophomonas maltophilia in mice, as indicated by a transient and minimal presence of the bacteria in animal organs after infection. S. maltophilia CF strains were shown to cause no mortality in a neonatal mouse model of respiratory tract infection (Waters et al., 2007). Despite this lack of strong invasiveness, mouse models of S. maltophilia infection have been useful answering questions about immune response against this pathogen (Brooke, 2012). Additionally, a model of acute respiratory infection in DBA/2 mice inoculated with aerosolized S. maltophilia has allowed the study of lung pathology and the mechanisms of infection resolution (Di Bonaventura et al., 2010). However, in this model, most of the animals were able to control the infection in a short time period, even at high doses of virulent inoculums, being the animal weight the best criterion to evaluate the virulence of tested strains (Di Bonaventura et al., 2010; Pompilio et al., 2011). One study also showed bacterial colonization in rat lungs after 7 days post-infection (McKay et al., 2003).

S. maltophilia has also been isolated from channel catfish (Ictalurus punctatus) with infectious intussusception syndrome (Geng et al., 2010), suggesting that the use of fish as a model to evaluate the pathogenicity and susceptibility of S. maltophilia to available antimicrobial agents is adequate. Recently, a model of intraperitoneal infection in zebrafish confirms the attenuation of a S. maltophilia collection strains when compared with recent clinical isolates (Ferrer-Navarro et al., 2013), paving the way for new approaches to gain relevant information on pathogenesis of this bacterium. An infection model using C. elegans has been proposed for routine screening of $S$. maltophila isolates for pathogenesis (Thomas et al., 2013). In this work the in vivo killing efficiency was evaluated by four different methods: classical fast killing assay, filter-based fast killing assay, slow killing assay and virulence assay using heat inactivated bacteria. Moreover, virulence regulation in S. maltophilia mediated by a quorum-sensing system has been recently studied in the $C$. elegans and zebrafish infection models (Huedo et al., 2014). In that work, it has been demonstrated that S. maltophilia inoculated by intraperitoneal route in zebrafish is characterized by rapid body dissemination. By the other hand, one study using the insect $G$. mellonella suggests the proteolysis as a possible pathogenic mechanism in S. maltophilia isolates from CF infections (Nicoletti et al., 2011).

On the other hand, respiratory pathogens like Burkholderia pseudomallei has the same type of tropism in mice than that observed in humans, regardless of its acute or chronic output (Stundick et al., 2013). Modeling of experimental melioidosis has been conducted in numerous biologically relevant models including mammalian and invertebrate hosts (reviewed in Warawa, 2010). Non-mammalian models have been explored since the 
mechanisms of Burkholderia virulence may be conserved during evolution from worms to mammals. Drosophila and G. mellonella have also shown to be useful alternative infection models for Burkholderia spp. (Castonguay-Vanier et al., 2010; Wand et al., 2011; Pilátová and Dionne, 2012). Particularly, Burkholderia thailandensis is highly virulent in the fruit fly (Pilátová and Dionne, 2012), a closely related organism to $B$. pseudomallei known to be avirulent in humans, thus being a useful model for mammalian melioidosis.

Data shown by O'Quinn et al. (2001) suggest that the disease phenotype observed in nematode after exposure to B. pseudomallei may be also valuable for investigating the pathogenesis of these bacteria. Burkholderia species are able to cause 'disease-like' symptoms and kill the nematode $C$. elegans either by infection or intoxication (O'Quinn et al., 2001; Darby, 2005) or suppressing worm immunity by specific degradation of a GATA transcription factor (Lee et al., 2013). The study of O'Quinn et al. (2001) suggests that the neuromuscular intoxication caused by B. pseudomallei is related to a signal transduction mechanism involving calcium. It is well-known that bacterial toxins can increase the content of free calcium $\left(\mathrm{Ca}^{2+}\right)$ in the cytosol of the host (TranVan Nhieu et al., 2004). In this sense, calcium acts as a second messenger in several physiological processes and immune mechanisms. The common respiratory bacterial pathogens, $P$. aeruginosa and $S$. aureus, activate $\mathrm{Ca}^{2+}$ fluxes after contact with y epithelial cells from the respiratory tract, activating proinflammatory signaling events (Ratner et al., 2001). The $\mathrm{Ca}^{2+}$ fluxes mediate the expression of proinflammatory cytokines and chemokines necessary to recruit leukocytes to the lung and also to initiate modifications in the epithelial junctions to facilitate leukocyte transmigration into the airway lumen (Chun and Prince, 2009). The C. elegans system has been used to screen for new virulence factors in $B$. pseudomallei, and selected attenuated bacterial mutants were further evaluated in an intranasal infection model in BALB/c mice (Gan et al., 2002). The results in mice validate positively the use and clinical relevance of $C$. elegans as an alternative model in the screening of virulence factors in B. pseudomallei.

\section{CONCLUDING REMARKS}

The nematode was the first invertebrate alternative model described, followed by the larvae and adult fruit fly models (Drosophila sp.) and more recently, the wax moth larvae (G. mellonella) model. Non-mammalian vertebrates, as fish and amphibians, which are able to mount an adaptive immune response, are now available as excellent tools. These kinds of models are usually criticized as being too distant from human. Several limitations such as their reduced complexity and the simplicity of their immune system, differences in temperature, target organs, or particular receptors have impaired the use of these models. However, these have been mentioned also for the murine models of other diseases. No model is perfect, each one has its specific strengths and weaknesses, but the most important thing is to combine the information gained from one to other, taking advantages of the incredible genomics and bioinformatics tools on-hand, before to extrapolate to humans beings. The belief that vertebrates are necessary the best available models in biomedical research was called the high-fidelity fallacy (Stevens, 1992; Russell, 1995). To avoid some of the limitations of these models, researchers begin to study infection and immunity in non-mammalian models. Since our knowledge of the immune system and their evolutionary conservation has increased, the usefulness of alternative models different for mammals has been accepted more. Although could seems irrational to study lung diseases in animals who do not have lungs, several evidences support the benefits that these studies, if carried properly, may to bring in the elucidation of human lung pathology diseases (Table 1). Thus, these non-mammalian organisms have been successfully employed to elucidate conserved and universal immune mechanisms. In addition, the small size of the most used non-mammalian organisms enables to perform high throughput and automated studies (Letamendia et al., 2012). Most of these model organisms have their genome completely sequenced, offering the possibility to do genetic studies both on the bacteria and the host. And what we consider one of the most practical advantages, the alternative models described here provide a way to easily bypass the ethical limitations of some types of studies in higher animal models.

What we do recommend to the scientific community facing the design of experimental infection with bacterial pathogens? Firstly, we have to consider several aspects related to the immunopathology of the diseases that we want to reproduce in an animal model. The relationship between the host and the guest in terms of molecular interactions is crucial to determine which type of response we will observe and consequently, to plan strategies for measuring it. But, a question arises. Which, among the methods that we will employ, are better in terms of cause less injury or damage to the animal? Is this response only measurable in vertebrate animal models? There are now sufficient evidences about the similarities of non-vertebrates immune systems and mammals. By other way, it has been demonstrated that the handling and maintenance of non-mammals organisms is easier and shaper. It is common to think in mice immediately when we are planning an in vivo experimental infection. Certainly, it is the most employed animal model in biomedical research. However, we could be aware about ethical restrictions that the use of large amount of animals and certain experimental procedures could implicate for the investigation. So, we modestly recommend being in mind the possibility of considering the use of no vertebrate animal models, as worms or insect as a first screening when it is reasonable. For the latter stages of the research we may to use other mammalian models. However, for certain lung diseases, conclusive points will arise more properly from the conjunction of one or more experimental studies carrying on in different species.

\section{AUTHOR CONTRIBUTIONS}

Yamilé L. Hernández and Daniel Yero authored first draft of manuscript with academic input and expertise provided by Isidre Gibert and Juan M. Pinos-Rodríguez. All authors were involved in reviewing manuscript and have approved the final version.

\section{ACKNOWLEDGMENTS}

The authors would like to acknowledge the significant review and the many valuable suggestions made by Nerea Roher, head of the group of Evolutive Immunology at IBB (Institut de Biotecnologia i de Biomedicina) and professor at the Departament de Biologia 
Cellular, Immunologia i Fisiologia Animal, Universitat Autònoma de Barcelona, Spain. Isidre Gibert and Daniel Yero acknowledge support from the Generalitat de Catalunya AGAUR (2014-SGR1280) and Ministerio de Economía y Competitividad, Spain (grant BFU2010-17199).

\section{REFERENCES}

Adamou, J. E., Heinrichs, J. H., Erwin, A. L., Walsh, W., Gayle, T., Dormitzer, M., et al. (2001). Identification and characterization of a novel family of pneumococcal proteins that are protective against sepsis. Infect. Immun. 69, 949-958. doi: 10.1128/IAI.69.2.949-958.2001

Aguilar, D., Hanekom, M., Mata, D., Gey van Pittius, N. C., van Helden, P. D., Warren, R. M., et al. (2010). Mycobacterium tuberculosis strains with the Beijing genotype demonstrate variability in virulence associated with transmission. Tuberculosis (Edinb.) 90, 319-325. doi: 10.1016/j.tube.2010. 08.004

Aguilar, D., Infante, E., Martin, C., Gormley, E., Gicquel, B., and Hernandez Pando, R. (2007). Immunological responses and protective immunity against tuberculosis conferred by vaccination of Balb/C mice with the attenuated Mycobacterium tuberculosis (phoP) SO2 strain. Clin. Exp. Immunol. 147, 330-338. doi: 10.1111/j.1365-2249.2006.03284.x

Alami, S. Y., Kelly, F. C., and Race, G. J. (1968). Pathogenicity of staphylococci: with special reference to the persitence of infection in mice. Am. J. Pathol. 53, 577-589.

Aldwell, F. E., Brandt, L., Fitzpatrick, C., and Orme, I. M. (2005). Mice fed lipid-encapsulated Mycobacterium bovis BCG are protected against aerosol challenge with Mycobacterium tuberculosis. Infect. Immun. 73, 1903-1905. doi: 10.1128/IAI.73.3.1903-1905.2005

Alejo, A., and Tafalla, C. (2011). Chemokines in teleost fish species. Dev. Comp. Immunol. 35, 1215-1222. doi: 10.1016/j.dci.2011.03.011

Ali, S., Champagne, D. L., Spaink, H. P., and Richardson, M. K. (2011). Zebrafish embryos and larvae: a new generation of disease models and drug screens. Birth Defects Res. C Embryo Today 93, 115-133. doi: 10.1002/bdrc.20206

Alper, S., Laws, R., Lackford, B., Boyd, W. A., Dunlap, P., Freedman, J. H., et al (2008). Identification of innate immunity genes and pathways using a comparative genomics approach. Proc. Natl. Acad. Sci. U.S.A. 105, 7016-7021. doi: 10.1073/pnas.0802405105

Alper, S., McElwee, M. K., Apfeld, J., Lackford, B., Freedman, J. H., and Schwartz, D. A. (2010). The Caenorhabditis elegans germ line regulates distinct signaling pathways to control lifespan and innate immunity. J. Biol. Chem. 285, 1822-1828. doi: 10.1074/jbc.M109.057323

Alvarez, N., Otero, O., Camacho, F., Borrero, R., Tirado, Y., Puig, A., et al. (2013). Passive administration of purified secretory IgA from human colostrum induces protection against Mycobacterium tuberculosis in a murine model of progressive pulmonary infection. BMC Immunol. 14(Suppl. 1):S3. doi: 10.1186/1471-217214-S1-S3

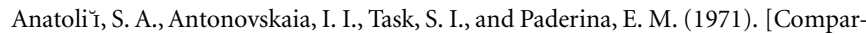
ative characteristics of some experimental models of staphylococcus infection]. Zh. Mikrobiol. Epidemiol. Immunobiol. 48, 60-63.

Andreevskaia, S. N., Chernousova, L. N., Smirnova, T. G., Larionova, E. E., and Kuz'min, A. V. (2007). [Impact of M. tuberculosis genotype on survival in mice with experimental tuberculosis]. Probl. Tuberk. Bolezn. Legk. 7, 45-50.

Ankeny, R. A. (2001). The natural history of Caenorhabditis elegans research. Nat. Rev. Genet. 2, 474-479. doi: 10.1038/35076538

Ansfield, M. J., Woods, D. E., and Johanson, W. G. Jr. (1977). Lung bacterial clearance in murine pneumococcal pneumonia. Infect. Immun. 17, 195-204.

Apolónio, J., Faleiro, M. L., Miguel, M. G., and Neto, L. (2014). No induction of antimicrobial resistance in Staphylococcus aureus and Listeria monocytogenes during continuous exposure to eugenol and citral. FEMS Microbiol. Lett. 354, 92-101. doi: 10.1111/1574-6968.12440

Apt, A. S. (2011). Are mouse models of human mycobacterial diseases relevant? Genetics says: “yes!” Immunology 134, 109-115. doi: 10.1111/j.13652567.2011.03472.x

Apt, A., and Kramnik, I. (2009). Man and mouse TB: contradictions and solutions. Tuberculosis (Edinb.) 89, 195-198. doi: 10.1016/j.tube.2009.02.002

Aziz, R. K., Kansal, R., Abdeltawab, N. F., Rowe, S. L., Su, Y., Carrigan, D., et al. (2007). Susceptibility to severe Streptococcal sepsis: use of a large set of isogenic mouse lines to study genetic and environmental factors. Genes Immun. 8, 404415. doi: $10.1038 /$ sj.gene.6364402
Bakker-Woudenberg, I. A. J. M. (2003). Experimental models of pulmonary infection. J. Microbiol. Methods 54, 295-313. doi: 10.1016/S0167-7012(03)00118-0

Bakker-Woudenberg, I. A., ten Kate, M. T., Guo, L., Working, P., and Mouton, J. W. (2002). Ciprofloxacin in polyethylene glycol-coated liposomes: efficacy in rat models of acute or chronic Pseudomonas aeruginosa infection. Antimicrob. Agents Chemother. 46, 2575-2581. doi: 10.1128/AAC.46.8.2575-2581.2002

Balloy, V., Verma, A., Kuravi, S., Si-Tahar, M., Chignard, M., and Ramphal, R. (2007). The role of flagellin versus motility in acute lung disease caused by Pseudomonas aeruginosa. J. Infect. Dis. 196, 289-296. doi: 10.1086/518610

Balls, M. (2009). The origins and early days of the Three Rs concept. Altern. Lab. Anim. 37, 255-265.

Balls, M., and Halder, M. (2002). Progress in applying the three Rs of Russell \& Burch to the testing of biological products. Dev. Biol. 111, 3-13.

Barbier, F., Andremont, A., Wolff, M., and Bouadma, L. (2013). Hospitalacquired pneumonia and ventilator-associated pneumonia: recent advances in epidemiology and management. Curr. Opin. Pulm. Med. 19, 216-228. doi: 10.1097/MCP.0b013e32835f27be

Bartell, P. F., Orr, T. E., Geffen, A., and Iorio, P. (1968). Experimental infection of mice with Staphylococcus aureus: evidence against alpha toxin and the terminal size of the bacterial population as determinants of lethality. J. Infect. Dis. 118, 481-490. doi: 10.1093/infdis/118.5.481

Baumans, V. (2004). Use of animals in experimental research: an ethical dilemma? Gene Ther. 11(Suppl. 1), S64-S66. doi: 10.1038/sj.gt.3302371

Baur, S., Rautenberg, M., Faulstich, M., Grau, T., Severin, Y., Unger, C., et al. (2014). A nasal epithelial receptor for Staphylococcus aureus WTA governs adhesion to epithelial cells and modulates nasal colonization. PLoS Pathog. 10:e1004089. doi: 10.1371/journal.ppat.1004089

Be, N. A., Lamichhane, G., Grosset, J., Tyagi, S., Cheng, Q.-J., Kim, K. S., et al. (2008). Murine model to study the invasion and survival of Mycobacterium tuberculosis in the central nervous system. J. Infect. Dis. 198, 1520-1528. doi: 10.1086/ 592447

Beale, E., Li, G., Tan, M.-W., and Rumbaugh, K. P. (2006). Caenorhabditis elegans senses bacterial autoinducers. Appl. Environ. Microbiol. 72, 5135-5137. doi: 10.1128/AEM.00611-06

Beamer, G. L., and Turner, J. (2005). Murine models of susceptibility to tuberculosis. Arch. Immunol. Ther. Exp. (Warsz.) 53, 469-483.

Begun, J., Gaiani, J. M., Rohde, H., Mack, D., Calderwood, S. B., Ausubel, F. M., et al. (2007). Staphylococcal biofilm exopolysaccharide protects against Caenorhabditis elegans immune defenses. PLoS Pathog. 3:e57. doi: 10.1371/journal.ppat.0030057

Begun, J., Sifri, C. D., Goldman, S., Calderwood, S. B., and Ausubel, F. M. (2005). Staphylococcus aureus virulence factors identified by using a highthroughput Caenorhabditis elegans-killing model. Infect. Immun. 73, 872-877. doi: 10.1128/IAI.73.2.872-877.2005

Bem, R. A., Domachowske, J. B., and Rosenberg, H. F. (2011). Animal models of human respiratory syncytial virus disease. Am. J. Physiol. Lung Cell. Mol. Physiol. 301, L148-L156. doi: 10.1152/ajplung.00065.2011

Benyumov, A. O., Hergert, P., Herrera, J., Peterson, M., Henke, C., and Bitterman, P. B. (2012). A novel zebrafish embryo xenotransplantation model to study primary human fibroblast motility in health and disease. Zebrafish 9, 38-43. doi: 10.1089/zeb.2011.0705

Berg, R. D., and Ramakrishnan, L. (2012). Insights into tuberculosis from the zebrafish model. Trends Mol. Med. 18, 689-690. doi: 10.1016/j.molmed.2012.10.002

Blair, C., Naclerio, R. M., Yu, X., Thompson, K., and Sperling, A. (2005). Role of type $1 \mathrm{~T}$ helper cells in the resolution of acute Streptococcus pneumoniae sinusitis: a mouse model. J. Infect. Dis. 192, 1237-1244. doi: 10.1086/444544

Bloemendaal, A. L. A., Vriens, M. R., Jansen, W. T. M., Borel Rinkes, I. H. M., Verhoef, J., and Fluit, A. C. (2011). Colonization and transmission of meticillinsusceptible and meticillin-resistant Staphylococcus aureus in a murine nasal colonization model. J. Med. Microbiol. 60, 812-816. doi: 10.1099/jmm.0. 027532-0

Boël, G., Jin, H., and Pancholi, V. (2005). Inhibition of cell surface export of group A streptococcal anchorless surface dehydrogenase affects bacterial adherence and antiphagocytic properties. Infect. Immun. 73, 6237-6248. doi: 10.1128/IAI.73.10.6237-6248.2005

Bogaert, D., Hermans, P. W. M., Adrian, P. V., Rümke, H. C., and de Groot, R. (2004). Pneumococcal vaccines: an update on current strategies. Vaccine 22, 2209-2220. doi: 10.1016/j.vaccine.2003.11.038 
Bolm, M., Jansen, W. T. M., Schnabel, R., and Chhatwal, G. S. (2004). Hydrogen peroxide-mediated killing of Caenorhabditis elegans: a common feature of different streptococcal species. Infect. Immun. 72, 1192-1194. doi: 10.1128/IAI.72.2.1192-1194.2004

Boman, H. G., Nilsson, I., and Rasmuson, B. (1972). Inducible antibacterial defence system in Drosophila. Nature 237, 232-235. doi: 10.1038/237232a0

Borst, L. B., Patterson, S. K., Lanka, S., Suyemoto, M. M., and Maddox, C. W. (2013). Zebrafish (Danio rerio) as a screen for attenuation of Lancefield group C streptococci and a model for streptococcal pathogenesis. Vet. Pathol. 50, 457-467. doi: 10.1177/0300985811424731

Bragonzi, A., Copreni, E., de Bentzmann, S., Ulrich, M., and Conese, M. (2004) Airway epithelial cell-pathogen interactions. J. Cyst. Fibros. 3(Suppl. 2), 197-201. doi: 10.1016/j.jcf.2004.05.041

Brannon, M. K., Davis, J. M., Mathias, J. R., Hall, C. J., Emerson, J. C., Crosier, P. S., et al. (2009). Pseudomonas aeruginosa Type III secretion system interacts with phagocytes to modulate systemic infection of zebrafish embryos. Cell. Microbiol. 11, 755-768. doi: 10.1111/j.1462-5822.2009.01288.x

Briles, D. E., Hollingshead, S. K., Nabors, G. S., Paton, J. C., and Brooks-Walter, A. (2000). The potential for using protein vaccines to protect against otitis media caused by Streptococcus pneumoniae. Vaccine 19(Suppl. 1), S87-S95. doi: 10.1016/S0264-410X(00)00285-1

Brooke, J. S. (2012). Stenotrophomonas maltophilia: an emerging global opportunistic pathogen. Clin. Microbiol. Rev. 25, 2-41. doi: 10.1128/CMR 00019-11

Cambier, C. J., Takaki, K. K., Larson, R. P., Hernandez, R. E., Tobin, D. M., Urdahl, K. B., etal. (2014). Mycobacteria manipulate macrophage recruitment through coordinated use of membrane lipids. Nature 505, 218-222. doi: 10.1038 /nature12799

Cantas, L., Sørby, J. R. T., Aleström, P., and Sørum, H. (2012). Culturable gut microbiota diversity in zebrafish. Zebrafish 9, 26-37. doi: 10.1089/zeb.2011.0712

Cardona, P.-J., Gordillo, S., Díaz, J., Tapia, G., Amat, I., Pallarés, A., et al. (2003). Widespread bronchogenic dissemination makes DBA/2 mice more susceptible than C57BL/6 mice to experimental aerosol infection with Mycobacterium tuberculosis. Infect. Immun. 71, 5845-5854. doi: 10.1128/IAI.71.10.58455854.2003

Castillo-Rodal, A. I., Castañón-Arreola, M., Hernández-Pando, R., Calva, J. J., SadaDíaz, E., and López-Vidal, Y. (2006). Mycobacterium bovis BCG substrains confer different levels of protection against Mycobacterium tuberculosis infection in a $\mathrm{BALB} / \mathrm{c}$ model of progressive pulmonary tuberculosis. Infect. Immun. 74, 1718 1724. doi: 10.1128/IAI.74.3.1718-1724.2006

Castonguay-Vanier, J., Vial, L., Tremblay, J., and Déziel, E. (2010). Drosophila melanogaster as a model host for the Burkholderia cepacia complex. PLoS ONE 5:e11467. doi: 10.1371/journal.pone.0011467

Cezairliyan, B., Vinayavekhin, N., Grenfell-Lee, D., Yuen, G. J., Saghatelian, A., and Ausubel, F. M. (2013). Identification of Pseudomonas aeruginosa phenazines that kill Caenorhabditis elegans. PLoS Pathog. 9:e1003101. doi: 10.1371/journal.ppat.1003101

Chen, B., Weisbrod, T. R., Hsu, T., Sambandamurthy, V., Vieira-Cruz, D. Chibbaro, A., et al. (2011). Einstein Contained Aerosol Pulmonizer (ECAP) improved biosafety for multi-drug resistant (MDR) and extensively drug resistant (XDR) Mycobacterium tuberculosis aerosol infection studies. Appl. Biosaf. 16, 134-138.

Chmiel, J. F., Konstan, M. W., Knesebeck, J. E., Hilliard, J. B., Bonfield, T. L., Dawson, D. V., et al. (1999). IL-10 attenuates excessive inflammation in chronic Pseudomonas infection in mice. Am. J. Respir. Crit. Care Med. 160, 2040-2047. doi: 10.1164/ajrccm.160.6.9901043

Chun, J., and Prince, A. (2009). $\mathrm{Ca}^{2+}$ signaling in airway epithelial cells facilitates leukocyte recruitment and transepithelial migration. J. Leukoc. Biol. 86, 11351144. doi: 10.1189/jlb.0209072

Clatworthy, A. E., Lee, J. S.-W., Leibman, M., Kostun, Z., Davidson, A. J., and Hung, D. T. (2009). Pseudomonas aeruginosa infection of zebrafish involves both host and pathogen determinants. Infect. Immun. 77, 1293-1303. doi: 10.1128/IAI.01181-08

Collie, D., Govan, J., Wright, S., Thornton, E., Tennant, P., Smith, S., et al. (2013). A lung segmental model of chronic Pseudomonas infection in sheep. PLoS ONE 8:e67677. doi: 10.1371/journal.pone.0067677

Collins, J. F., Anzueto, A. A., Peters, J. I., de los Santos, R., Gonzalez, D. C., Johanson, W. G., et al. (1991). Elastase activity in bronchoalveolar lavage fluid from oxygen-exposed, Pseudomonas-infected baboons. Lung 169, 165-179. doi: $10.1007 / \mathrm{BF} 02714152$

Cooper, A. M. (2014). Mouse model of tuberculosis. Cold Spring Harb. Perspect. Med. doi: 10.1101/cshperspect.a018556 [Epub ahead of print].

Cosma, C. L., Klein, K., Kim, R., Beery, D., and Ramakrishnan, L. (2006a). Mycobacterium marinum Erp is a virulence determinant required for cell wall integrity and intracellular survival. Infect. Immun. 74, 3125-3133. doi: 10.1128/IAI.02061-05

Cosma, C. L., Swaim, L. E., Volkman, H., Ramakrishnan, L., and Davis, J. M. (2006b). Zebrafish and frog models of Mycobacterium marinum infection. Curr. Protoc. Microbiol. Chap. 10, Unit 10B.2. doi: 10.1002/0471729256.mc10b02s3

Couillault, C., and Ewbank, J. J. (2002). Diverse bacteria are pathogens of Caenorhabditis elegans. Infect. Immun. 70, 4705-4707. doi: 10.1128/IAI.70.8.4705-4707.2002

Coutinho, H. D. M., Falcao-Silva, V. S., and Goncalves, G. F. (2008). Pulmonary bacterial pathogens in cystic fibrosis patients and antibiotic therapy: a tool for the health workers. Int. Arch. Med. 1, 24. doi: 10.1186/1755-7682-1-24

Cressey, D. (2014). Fish-kill method questioned. Nature 506, 419-420. doi: $10.1038 / 506419 a$

Cronan, M. R., and Tobin, D. M. (2014). Fit for consumption: zebrafish as a model for tuberculosis. Dis. Model. Mech. 7, 777-784. doi: 10.1242/dmm.016089

Cui, C., Benard, E. L., Kanwal, Z., Stockhammer, O. W., van der Vaart, M., Zakrzewska, A., etal. (2011). Infectious disease modeling and innate immune function in zebrafish embryos. Methods Cell Biol. 105, 273-308. doi: 10.1016/B978-0-12-381320-6.00012-6

Damy, S. B., Camargo, R. S., Chammas, R., and Figueiredo, L. F. (2010). [Fundamental aspects on animal research as applied to experimental surgery]. Rev. Assoc. Med. Bras. 1992 56, 103-111. doi: 10.1590/S0104-42302010000100024

Darby, C. (2005). "Interactions with microbial pathogens," in WormBook, ed. The C. elegans Research Community, WormBook. doi: 10.1895/wormbook.1.21.1

D’Argenio, D. A., Gallagher, L. A., Berg, C. A., and Manoil, C. (2001). Drosophila as a model host for Pseudomonas aeruginosa infection. J. Bacteriol. 183, 1466-1471. doi: 10.1128/JB.183.4.1466-1471.2001

Davis, J. M., Clay, H., Lewis, J. L., Ghori, N., Herbomel, P., and Ramakrishnan, L. (2002). Real-time visualization of mycobacterium-macrophage interactions leading to initiation of granuloma formation in zebrafish embryos. Immunity 17 , 693-702. doi: 10.1016/S1074-7613(02)00475-2

Davis, J. M., and Ramakrishnan, L. (2009). The role of the granuloma in expansion and dissemination of early tuberculous infection. Cell 136, 37-49. doi: 10.1016/j.cell.2008.11.014

Dean, S. N., Bishop, B. M., and van Hoek, M. L. (2011). Susceptibility of Pseudomonas aeruginosa Biofilm to Alpha-Helical Peptides: D-enantiomer of LL-37. Front. Microbiol. 2:128. doi: 10.3389/fmicb.2011.00128

Denny, P. (2005). Editorial. Mouse models of infectious disease. Brief. Funct. Genomic. Proteomic. 4, 201-202. doi: 10.1093/bfgp/4.3.201

Desbois, A. P., and Coote, P. J. (2011). Wax moth larva (Galleria mellonella): an in vivo model for assessing the efficacy of antistaphylococcal agents. J. Antimicrob. Chemother. 66, 1785-1790. doi: 10.1093/jac/dkr198

De Steenwinkel, J. E. M., De Knegt, G. J., Ten Kate, M. T., Van Belkum, A., Verbrugh, H. A., Hernandez-Pando, R., et al. (2009). Immunological parameters to define infection progression and therapy response in a well-defined tuberculosis model in mice. Int. J. Immunopathol. Pharmacol. 22, 723-734.

Dharmadhikari, A. S., and Nardell, E. A. (2008). What animal models teach humans about tuberculosis. Am. J. Respir. Cell Mol. Biol. 39, 503-508. doi: 10.1165/rcmb.2008-0154TR

Di Bonaventura, G., Pompilio, A., Zappacosta, R., Petrucci, F., Fiscarelli, E., Rossi, C., et al. (2010). Role of excessive inflammatory response to Stenotrophomonas maltophilia lung infection in DBA/2 mice and implications for cystic fibrosis. Infect. Immun. 78, 2466-2476. doi: 10.1128/IAI.01391-09

Dionne, M. S., Ghori, N., and Schneider, D. S. (2003). Drosophila melanogaster is a genetically tractable model host for Mycobacterium marinum. Infect. Immun. 71, 3540-3550. doi: 10.1128/IAI.71.6.3540-3550.2003

Di Pietrantonio, T., and Schurr, E. (2005). Mouse models for the genetic study of tuberculosis susceptibility. Brief. Funct. Genomic. Proteomic. 4, 277-292. doi: 10.1093/bfgp/4.3.277

Dunbar, T. L., Yan, Z., Balla, K. M., Smelkinson, M. G., and Troemel, E. R. (2012). C. elegans detects pathogen-induced translational inhibition to activate immune signaling. Cell Host Microbe 11, 375-386. doi: 10.1016/j.chom.2012.02.008

Endo, Y., Takahashi, M., Iwaki, D., Ishida, Y., Nakazawa, N., Kodama, T., et al. (2012). Mice deficient in ficolin, a lectin complement pathway recognition molecule, are 
susceptible to Streptococcus pneumoniae infection. J. Immunol. 189, 5860-5866. doi: 10.4049/jimmunol.1200836

Erdem, H., Inan, A., Alt $ı$ ndis, S., Carevic, B., Askarian, M., Cottle, L., et al. (2014). Surveillance, control and management of infections in intensive care units in Southern Europe, Turkey and Iran - a prospective multicenter point prevalence study. J. Infect. 68, 131-140. doi: 10.1016/j.jinf.2013.11.001

Evans, B. A., and Rozen, D. E. (2012). A Streptococcus pneumoniae infection model in larvae of the wax moth Galleria mellonella. Eur. J. Clin. Microbiol. Infect. Dis. 31, 2653-2660. doi: 10.1007/s10096-012-1609-7

Evans, S. E., Tuvim, M. J., Zhang, J., Larson, D. T., García, C. D., Martinez-Pro, S., et al. (2010). Host lung gene expression patterns predict infectious etiology in a mouse model of pneumonia. Respir. Res. 11:101. doi: 10.1186/1465-9921-11-101

Feinbaum, R. L., Urbach, J. M., Liberati, N. T., Djonovic, S., Adonizio, A., Carvunis, A.-R., et al. (2012). Genome-Wide Identification of Pseudomonas aeruginosa virulence-related genes using a Caenorhabditis elegans infection model. PLoS Pathog. 8:e1002813. doi: 10.1371/journal.ppat.1002813

Fernandes, C. A., and Vanbever, R. (2009). Preclinical models for pulmonary drug delivery. Expert Opin. Drug Deliv. 6, 1231-1245. doi $10.1517 / 17425240903241788$

Fernandez, S., Cisney, E. D., Hall, S. I., and Ulrich, R. G. (2011). Nasal immunity to staphylococcal toxic shock is controlled by the nasopharynx-associated lymphoid tissue. Clin. Vaccine Immunol. 18, 667-675. doi: 10.1128/CVI.00477-10

Ferrer-Navarro, M., Planell, R., Yero, D., Mongiardini, E., Torrent, G., Huedo, P., et al. (2013). Abundance of the Quorum-Sensing factor Ax21 in four strains of Stenotrophomonas maltophilia correlates with mortality rate in a New Zebrafish model of infection. PLOS ONE 8:e67207. doi: 10.1371/journal.pone.0067207

Fuchs, H., Gailus-Durner, V., Adler, T., Pimentel, J. A. A., Becker, L., Bolle, I., etal. (2009). The German mouse clinic: a platform for systemic phenotype analysis of mouse models. Curr. Pharm. Biotechnol. 10, 236-243. doi: $10.2174 / 138920109787315051$

Gan, Y.-H., Chua, K. L., Chua, H. H., Liu, B., Hii, C. S., Chong, H. L., et al. (2002). Characterization of Burkholderia pseudomallei infection and identification of novel virulence factors using a Caenorhabditis elegans host system. Mol. Microbiol. 44, 1185-1197. doi: 10.1046/j.1365-2958.2002.02957.x

Gao, W., Chua, K., Davies, J. K., Newton, H. J., Seemann, T., Harrison, P. F., et al. (2010). Two novel point mutations in clinical Staphylococcus aureus reduce linezolid susceptibility and switch on the stringent response to promote persistent infection. PLoS Pathog. 6:e1000944. doi: 10.1371/journal.ppat.1000944

Garsin, D. A., Sifri, C. D., Mylonakis, E., Qin, X., Singh, K. V., Murray, B. E., et al. (2001). A simple model host for identifying Gram-positive virulence factors. Proc. Natl. Acad. Sci. U.S.A. 98, 10892-10897. doi: 10.1073/pnas.191378698

Garsin, D. A., Villanueva, J. M., Begun, J., Kim, D. H., Sifri, C. D., Calderwood, S. B., et al. (2003). Long-lived C. elegans daf-2 mutants are resistant to bacterial pathogens. Science 300:1921. doi: 10.1126/science.1080147

Geng, Y., Wang, K., Chen, D., Huang, X., He, M., and Yin, Z. (2010) Stenotrophomonas maltophilia, an emerging opportunist pathogen for cultured channel catfish, Ictalurus punctatus, in China. Aquaculture 308, 132-135. doi: 10.1016/j.aquaculture.2010.08.032

George, S. E., Kohan, M. J., Whitehouse, D. A., Creason, J. P., Kawanishi, C. Y., Sherwood, R. L., et al. (1991). Distribution, clearance, and mortality of environmental pseudomonads in mice upon intranasal exposure. Appl. Environ. Microbiol. 57, 2420-2425.

Gerber, J., Raivich, G., Wellmer, A., Noeske, C., Kunst, T., Werner, A., et al. (2001). A mouse model of Streptococcus pneumoniae meningitis mimicking several features of human disease. Acta Neuropathol. (Berl.) 101, 499-508.

Gibreel, T. M., and Upton, M. (2013). Synthetic epidermicin NI01 can protect Galleria mellonella larvae from infection with Staphylococcus aureus. J. Antimicrob. Chemother. 68, 2269-2273. doi: 10.1093/jac/dkt195

Glavis-Bloom, J., Muhammed, M., and Mylonakis, E. (2012). Of model hosts and man: using Caenorhabditis elegans, Drosophila melanogaster and Galleria mellonella as model hosts for infectious disease research. Adv. Exp. Med. Biol. 710 11-17. doi: 10.1007/978-1-4419-5638-5_2

Gosselin, D., DeSanctis, J., Boulé, M., Skamene, E., Matouk, C., and Radzioch, D. (1995). Role of tumor necrosis factor alpha in innate resistance to mouse pulmonary infection with Pseudomonas aeruginosa. Infect. Immun. 63, 32723278. doi: 10.1007/978-1-4419-5638-5_2

Gosselin, D., Stevenson, M. M., Cowley, E. A., Griesenbach, U., Eidelman, D. H., Boulé, M., et al. (1998). Impaired ability of Cftr knockout mice to control lung infection with Pseudomonas aeruginosa. Am. J. Respir. Crit. Care Med. 157, 12531262. doi: 10.1164/ajrccm.157.4.9702081

Green, R. M., Gally, F., Keeney, J. G., Alper, S., Gao, B., Han, M., et al. (2009). Impact of cigarette smoke exposure on innate immunity: a Caenorhabditis elegans model. PLoS ONE 4:e6860. doi: 10.1371/journal.pone.0006860

Grumbach, F., Canetti, G., Grosset, J., and le Lirzin, M. (1967). Late results of longterm intermittent chemotherapy of advanced, murine tuberculosis: limits of the murine model. Tubercle 48, 11-26. doi: 10.1016/S0041-3879(67)80047-3

Hall, A. E., Patel, P. R., Domanski, P. J., Prater, B. D., Gorovits, E. L., Syribeys, P. J., et al. (2007). A panel of monoclonal antibodies recognizing the Staphylococcus epidermidis fibrinogen-binding MSCRAMM SdrG. Hybridoma 26, 28-34. doi: $10.1089 /$ hyb.2006.039

Hammarén, M. M., Oksanen, K. E., Nisula, H. M., Luukinen, B. V., Pesu, M., Rämet, M., et al. (2014). Adequate Th2-type response associates with restricted bacterial growth in latent mycobacterial infection of zebrafish. PLoS Pathog. 10:e1004190. doi: 10.1371/journal.ppat.1004190

Hart, D. A., Green, F., Whidden, P., Henkin, J., and Woods, D. E. (1993). Exogenous rh-urokinase modifies inflammation and Pseudomonas aeruginosa infection in a rat chronic pulmonary infection model. Can. J. Microbiol. 39, 1127-1134. doi: $10.1139 / \mathrm{m} 93-170$

Hendriksen, C. F. M. (2002). Refinement, reduction, and replacement of animal use for regulatory testing: current best scientific practices for the evaluation of safety and potency of biologicals. ILAR J. 43(Suppl.), S43-S48.

Hernandez-Pando, R., de la Luz Streber, M., Orozco, H., Arriaga, K., Pavon, L., Marti, O., et al. (1998). Emergent immunoregulatory properties of combined glucocorticoid and anti-glucocorticoid steroids in a model of tuberculosis. QJM 91, 755-766. doi: 10.1093/qjmed/91.11.755

Hernández-Pando, R., Orozcoe, H., Sampieri, A., Pavón, L., Velasquillo, C., Larriva-Sahd, J., et al. (1996). Correlation between the kinetics of Th1, Th2 cells and pathology in a murine model of experimental pulmonary tuberculosis. Immunology 89, 26-33.

Holland, M. C. H., and Lambris, J. D. (2004). A functional C5a anaphylatoxin receptor in a teleost species. J. Immunol. 172, 349-355. doi: 10.4049/jimmunol.172.1.349

Hu, D.-L., Omoe, K., Narita, K., Cui, J.-C., Shinagawa, K., and Nakane, A. (2006). Intranasal vaccination with a double mutant of staphylococcal enterotoxin $\mathrm{C}$ provides protection against Staphylococcus aureus infection. Microbes Infect. 8, 2841-2848. doi: 10.1016/j.micinf.2006.09.001

Huedo, P., Yero, D., Martínez-Servat, S., Estibariz, I., Planell, R., Martínez, P., et al. (2014). Two different rpf clusters distributed among a population of Stenotrophomonas maltophilia clinical strains display differential diffusible signal factor production and virulence regulation. J. Bacteriol. 196, 2431-2442. doi: 10.1128/JB.01540-14

Hulme, S. E., and Whitesides, G. M. (2011). Chemistry and the worm: Caenorhabditis elegans as a platform for integrating chemical and biological research. Angew. Chem. Int. Ed. Engl. 50, 4774-4807. doi: 10.1002/anie.201005461

Hunter, R. L., Jagannath, C., and Actor, J. K. (2007). Pathology of postprimary tuberculosis in humans and mice: contradiction of long-held beliefs. Tuberculosis (Edinb.) 87, 267-278. doi: 10.1016/j.tube.2006.11.003

Huzella, L. M., Buckley, M. J., Alves, D. A., Stiles, B. G., and Krakauer, T. (2009). Central roles for IL-2 and MCP-1 following intranasal exposure to SEB: a new mouse model. Res. Vet. Sci. 86, 241-247. doi: 10.1016/j.rvsc.2008. 07.020

Hyde, D. M., Hamid, Q., and Irvin, C. G. (2009). Anatomy, pathology, and physiology of the tracheobronchial tree: emphasis on the distal airways. J. Allergy Clin. Immunol. 124, S72-S77. doi: 10.1016/j.jaci.2009.08.048

Igboin, C. O., Griffen, A. L., and Leys, E. J. (2012). The Drosophila melanogaster host model. J. Oral Microbiol. 4:10368. doi: 10.3402/jom.v4i0.10368

Irvin, C. G., and Bates, J. H. T. (2003). Measuring the lung function in the mouse: the challenge of size. Respir. Res. 4:4. doi: 10.1186/rr199

Iwata, M., and Sato, A. (1991). Morphological and immunohistochemical studies of the lungs and bronchus-associated lymphoid tissue in a rat model of chronic pulmonary infection with Pseudomonas aeruginosa. Infect. Immun. 59, 15141520 .

Jain, M., Bar-Meir, M., McColley, S., Cullina, J., Potter, E., Powers, C., et al. (2008). Evolution of Pseudomonas aeruginosa type III secretion in cystic fibrosis: a paradigm of chronic infection. Transl. Res. J. Lab. Clin. Med. 152, 257-264. doi: 10.1016/j.trsl.2008.10.003 
Jakab, G. J. (1976). Factors influencing the immune enhancement of intrapulmonary bactericidal mechanisms. Infect. Immun. 14, 389-398.

Jander, G., Rahme, L. G., and Ausubel, F. M. (2000). Positive correlation between virulence of Pseudomonas aeruginosa mutants in mice and insects. J. Bacteriol. 182, 3843-3845. doi: 10.1128/JB.182.13.3843-3845.2000

Jansen, W. T. M., Bolm, M., Balling, R., Chhatwal, G. S., and Schnabel, R. (2002). Hydrogen peroxide-mediated killing of Caenorhabditis elegans by Streptococcus pyogenes. Infect. Immun. 70, 5202-5207. doi: 10.1128/IAI.70.9.5202-5207.2002

JebaMercy, G., Pandian, S. K., and Balamurugan, K. (2011). Changes in Caenorhabditis elegans life span and selective innate immune genes during Staphylococcus aureus infection. Folia Microbiol. (Praha) 56, 373-380. doi: 10.1007/s12223-011-0060-y

Jones, R. N. (2010). Microbial etiologies of hospital-acquired bacterial pneumonia and ventilator-associated bacterial pneumonia. Clin. Infect. Dis. 51(Suppl. 1), S81-S87. doi: 10.1086/653053

Kadioglu, A., and Andrew, P. W. (2004). The innate immune response to pneumococcal lung infection: the untold story. Trends Immunol. 25, 143-149. doi: 10.1016/j.it.2003.12.006

Kanther, M., and Rawls, J. F. (2010). Host-microbe interactions in the developing zebrafish. Curr. Opin. Immunol. 22, 10-19. doi: 10.1016/j.coi.2010.01.006

Karakousis, P. C., Yoshimatsu, T., Lamichhane, G., Woolwine, S. C., Nuermberger, E. L., Grosset, J., et al. (2004). Dormancy phenotype displayed by extracellular Mycobacterium tuberculosis within artificial granulomas in mice. J. Exp. Med. 200 647-657. doi: 10.1084/jem.20040646

Kato, J., Kim, H.-E., Takiguchi, N., Kuroda, A., and Ohtake, H. (2008). Pseudomona aeruginosa as a model microorganism for investigation of chemotactic behaviors in ecosystem. J. Biosci. Bioeng. 106, 1-7. doi: 10.1263/jbb.106.1

Kaushal, D., Mehra, S., Didier, P. J., and Lackner, A. A. (2012). The non-human primate model of tuberculosis. J. Med. Primatol. 41, 191-201. doi: 10.1111/j.16000684.2012.00536.x

Kelly, B. P., Furney, S. K., Jessen, M. T., and Orme, I. M. (1996). Low-dose aerosol infection model for testing drugs for efficacy against Mycobacterium tuberculosis. Antimicrob. Agents Chemother. 40, 2809-2812.

Kim, D. H., Feinbaum, R., Alloing, G., Emerson, F. E., Garsin, D. A., Inoue, H., et al. (2002). A conserved p38 MAP kinase pathway in Caenorhabditis elegans innate immunity. Science 297, 623-626. doi: 10.1126/science.1073759

Kubica, M., Guzik, K., Koziel, J., Zarebski, M., Richter, W., Gajkowska, B., etal. (2008). A potential new pathway for Staphylococcus aureus dissemination: the silent survival of $S$. aureus phagocytosed by human monocyte-derived macrophages. PLoS ONE 3:e1409. doi: 10.1371/journal.pone. 0001409

Kurahashi, K., Sawa, T., Ota, M., Kajikawa, O., Hong, K., Martin, T. R., et al. (2009). Depletion of phagocytes in the reticuloendothelial system causes increased inflammation and mortality in rabbits with Pseudomonas aeruginosa pneumonia. Am. J. Physiol. Lung Cell. Mol. Physiol. 296, L198-L209. doi: 10.1152/ajplung.90472.2008

Kurz, C. L., and Ewbank, J. J. (2000). Caenorhabditis elegans for the study of host-pathogen interactions. Trends Microbiol. 8, 142-144. doi: 10.1016/S0966842X(99)01691-1

Kurz, C. L., and Ewbank, J. J. (2007). Infection in a dish: high-throughput analyses of bacterial pathogenesis. Curr. Opin. Microbiol. 10, 10-16. doi: 10.1016/j.mib.2006.12.001

Lebeaux, D., Chauhan, A., Rendueles, O., and Beloin, C. (2013). From in vitro to in vivo models of bacterial Biofilm-related infections. Pathogens 2, 288-356. doi: 10.3390/pathogens2020288

Ledizet, M., Murray, T. S., Puttagunta, S., Slade, M. D., Quagliarello, V. J., and Kazmierczak, B. I. (2012). The ability of virulence factor expression by Pseudomonas aeruginosa to predict clinical disease in hospitalized patients. PLoS ONE 7:e49578. doi: 10.1371/journal.pone.0049578

Lee, S.-H., Wong, R.-R., Chin, C.-Y., Lim, T.-Y., Eng, S.-A., Kong, C., et al. (2013). Burkholderia pseudomallei suppresses Caenorhabditis elegans immunity by specific degradation of a GATA transcription factor. Proc. Natl. Acad. Sci. U.S.A. 110, 15067-15072. doi: 10.1073/pnas.1311725110

Lemaitre, B., and Hoffmann, J. (2007). The host defense of Drosophila melanogaster. Annu. Rev. Immunol. 25, 697-743. doi: 10.1146/annurev.immunol.25.022106. 141615

Letamendia, A., Quevedo, C., Ibarbia, I., Virto, J. M., Holgado, O., Diez, M., et al. (2012). Development and validation of an automated high-throughput system for zebrafish in vivo screenings. PLoS ONE 7:e36690. doi: 10.1371/journal.pone. 0036690

Leung, C., Chijioke, O., Gujer, C., Chatterjee, B., Antsiferova, O., Landtwing, V., et al. (2013). Infectious diseases in humanized mice. Eur. J. Immunol. 43, 2246-2254. doi: 10.1002/eji.201343815

Li, Y., and Hu, B. (2012). Establishment of multi-site infection model in zebrafish larvae for studying Staphylococcus aureus infectious disease. J. Genet. Genomics 39, 521-534. doi: 10.1016/j.jgg.2012.07.006

Limmer, S., Quintin, J., Hetru, C., and Ferrandon, D. (2011). Virulence on the fly: Drosophila melanogaster as a model genetic organism to decipher host-pathogen interactions. Curr. Drug Targets 12, 978-999. doi: 10.2174/138945011795677818

Lin, B., Chen, S., Cao, Z., Lin, Y., Mo, D., Zhang, H., et al. (2007). Acute phase response in zebrafish upon Aeromonas salmonicida and Staphylococcus aureus infection: striking similarities and obvious differences with mammals. Mol. Immunol. 44, 295-301. doi: 10.1016/j.molimm.2006.03.001

Lipscomb, M. F., Hutt, J., Lovchik, J., Wu, T., and Lyons, C. R. (2010). The pathogenesis of acute pulmonary viral and bacterial infections: investigations in animal models. Annu. Rev. Pathol. 5, 223-252. doi: 10.1146/annurev-pathol-121808102153

López, Y., Falero-Díaz, G., Yero, D., Solís, R. L., Sarmiento, M. E., and Acosta, A. (2010). Antibodies in the protection against mycobacterial infections: what have we learned? Procedia Vaccinol. 2, 172-177. doi: 10.1016/j.provac.2010.07.011

López, Y., Yero, D., Falero-Diaz, G., Olivares, N., Sarmiento, M. E., Sifontes, S., et al. (2009). Induction of a protective response with an IgA monoclonal antibody against Mycobacterium tuberculosis $16 \mathrm{kDa}$ protein in a model of progressive pulmonary infection. Int. J. Med. Microbiol. 299, 447-452. doi: 10.1016/j.ijmm.2008.10.007

López, Y., Yero, D., Rodríguez, S. S., Infante Bourzac, J. F., Sarmiento, M. E., Arzuaga, N. O., et al. (2006). Immunization of mice with a Mycobacterium tuberculosis genomic expression library results in lower bacterial load in lungs after challenge with BCG. Tuberculosis (Edinb.) 86, 247-254. doi: 10.1016/j.tube.2006.01.004

Lü, A.-J., Hu, X.-C., Wang, Y., Ming, Q.-L., and Hu, H.-X. (2012). Immune response in the skin of zebrafish, Danio rerio (Hamilton), against Staphylococcus chromogenes. J. Fish Dis. 35, 699-704. doi: 10.1111/j.1365-2761.2012.01371.x

Lugo-Villarino, G., Balla, K. M., Stachura, D. L., Bañuelos, K., Werneck, M. B. F., and Traver, D. (2010). Identification of dendritic antigen-presenting cells in the zebrafish. Proc. Natl. Acad. Sci. U.S.A. 107, 15850-15855. doi: 10.1073/pnas.1000494107

Luna, C. M., Baquero, S., Gando, S., Patrón, J. R., Morato, J. G., Sibila, O., et al. (2007). Experimental severe Pseudomonas aeruginosa pneumonia and antibiotic therapy in piglets receiving mechanical ventilation. Chest 132, 523-531. doi: 10.1378/chest.07-0185

Luna, C. M., Sibila, O., Agusti, C., and Torres, A. (2009). Animal models of ventilator-associated pneumonia. Eur. Respir. J. 33, 182-188. doi: 10.1183/09031936.00046308

Lyons, C. R., Lovchik, J., Hutt, J., Lipscomb, M. F., Wang, E., Heninger, S., et al. (2004). Murine model of pulmonary anthrax: kinetics of dissemination, histopathology, and mouse strain susceptibility. Infect. Immun. 72, 4801-4809. doi: 10.1128/IAI.72.8.4801-4809.2004

Mall, M. A. (2008). Role of cilia, mucus, and airway surface liquid in mucociliary dysfunction: lessons from mouse models. J. Aerosol Med. Pulm. Drug Deliv. 21, 13-24. doi: 10.1089/jamp.2007.0659

Mall, M., Grubb, B. R., Harkema, J. R., O’Neal, W. K., and Boucher, R. C. (2004). Increased airway epithelial $\mathrm{Na}^{+}$absorption produces cystic fibrosis-like lung disease in mice. Nat. Med. 10, 487-493. doi: 10.1038/nm1028

Martin, J. S., and Renshaw, S. A. (2009). Using in vivo zebrafish models to understand the biochemical basis of neutrophilic respiratory disease. Biochem. Soc. Trans. 37, 830-837. doi: 10.1042/BST0370830

Mason, C. M., Kolls, J. K., and Nelson, S. (1995). Pathogenesis and host defense in pulmonary infections. Curr. Opin. Pulm. Med. 1, 163-170.

McKay, G. A., Woods, D. E., MacDonald, K. L., and Poole, K. (2003). Role of phosphoglucomutase of Stenotrophomonas maltophilia in lipopolysaccharide biosynthesis, virulence, and antibiotic resistance. Infect. Immun. 71, 3068-3075. doi: 10.1128/IAI.71.6.3068-3075.2003

McMorran, B. J., Palmer, J. S., Lunn, D. P., Oceandy, D., Costelloe, E. O., Thomas, G. R., et al. (2001). G551D CF mice display an abnormal host response and have impaired clearance of Pseudomonas lung disease. Am. J. Physiol. Lung Cell. Mol. Physiol. 281, L740-L747. 
Means, T. K., and Aballay, A. (2011). Models to study ancient host-pathogen interactions: lessons from Crete. EMBO Rep. 12, 5-7. doi: 10.1038/embor.2010.205

Meeker, N. D., and Trede, N. S. (2008). Immunology and zebrafish: spawning new models of human disease. Dev. Comp. Immunol. 32, 745-757. doi: 10.1016/j.dci.2007.11.011

Meijer, A. H., and Spaink, H. P. (2011). Host-pathogen interactions made transparent with the zebrafish model. Curr. Drug Targets 12, 1000-1017. doi: $10.2174 / 138945011795677809$

Mitra, S., Alnabulsi, A., Secombes, C. J., and Bird, S. (2010). Identification and characterization of the transcription factors involved in T-cell development, $\mathrm{t}$ bet, stat 6 and foxp3, within the zebrafish, Danio rerio. FEBS J. 277, 128-147. doi: $10.1111 / j .1742-4658.2009 .07460 . x$

Mizgerd, J. P., and Skerrett, S. J. (2008). Animal models of human pneumonia. Am. J. Physiol. Lung Cell. Mol. Physiol. 294, L387-L398. doi: 10.1152/ajplung.00330.2007

Mollenkopf, H.-J., Kursar, M., and Kaufmann, S. H. E. (2004). Immune response to postprimary tuberculosis in mice: Mycobacterium tuberculosis and Mycobacterium bovis bacille Calmette-Guérin induce equal protection. J. Infect. Dis. 190, 588-597. doi: $10.1086 / 422394$.

Moreau-Marquis, S., Stanton, B. A., and O’Toole, G. A. (2008). Pseudomonas aeruginosa biofilm formation in the cystic fibrosis airway. Pulm. Pharmacol. Ther. 21, 595-599. doi: 10.1016/j.pupt.2007.12.001

Morissette, C., Skamene, E., and Gervais, F. (1995). Endobronchial inflammation following Pseudomonas aeruginosa infection in resistant and susceptible strains of mice. Infect. Immun. 63, 1718-1724.

Morsczeck, C., Prokhorova, T., Sigh, J., Pfeiffer, M., Bille-Nielsen, M., Petersen, J., et al. (2008). Streptococcus pneumoniae: proteomics of surface proteins for vaccine development. Clin. Microbiol. Infect. 14, 74-81. doi: 10.1111/j.14690691.2007.01878.x

Moser, C., Jensen, P. O., Kobayashi, O., Hougen, H. P., Song, Z., Rygaard, J., et al. (2002). Improved outcome of chronic Pseudomonas aeruginosa lung infection is associated with induction of a Th1-dominated cytokine response. Clin. Exp. Immunol. 127, 206-213. doi: 10.1046/j.1365-2249.2002. 01731.x

Moser, C., Johansen, H. K., Song, Z., Hougen, H. P., Rygaard, J., and Høiby, N. (1997). Chronic Pseudomonas aeruginosa lung infection is more severe in Th2 responding BALB/c mice compared to Th1 responding $\mathrm{C} 3 \mathrm{H} / \mathrm{HeN}$ mice. Acta Pathol. Microbiol. Immunol. Scand. 105, 838-842. doi: 10.1111/j.16990463.1997.tb05092.x

Mulcahy, H., Sibley, C. D., Surette, M. G., and Lewenza, S. (2011). Drosophila melanogaster as an animal model for the study of Pseudomonas aeruginosa Biofilm Infections in vivo. PLoS Pathog. 7:e1002299. doi: 10.1371/journal.ppat. 1002299

Musher, D. M., and Thorner, A. R. (2014). Community-acquired pneumonia. N. Engl. J. Med. 371, 1619-1628. doi: 10.1056/NEJMra1312885

Mustafa, T., Phyu, S., Nilsen, R., Bjune, G., and Jonsson, R. (1999a). Increased expression of Fas ligand on Mycobacterium tuberculosis infected macrophages: a potential novel mechanism of immune evasion by Mycobacterium tuberculosis? Inflammation 23, 507-521.

Mustafa, T., Phyu, S., Nilsen, R., Jonsson, R., and Bjune, G. (1999b). A mouse model for slowly progressive primary tuberculosis. Scand. J. Immunol. 50, 127-136. doi: 10.1046/j.1365-3083.1999.00596.x

Mustafa, T., Phyu, S., Nilsen, R., Jonsson, R., and Bjune, G. (2000). In situ expression of cytokines and cellular phenotypes in the lungs of mice with slowly progressive primary tuberculosis. Scand. J. Immunol. 51, 548-556. doi: 10.1046/j.1365-3083.2000.00721.x

Nicoletti, M., Iacobino, A., Prosseda, G., Fiscarelli, E., Zarrilli, R., De Carolis, E., et al. (2011). Stenotrophomonas maltophilia strains from cystic fibrosis patients: genomic variability and molecular characterization of some virulence determinants. Int. J. Med. Microbiol. 301, 34-43. doi: 10.1016/j.ijmm.2010. 07.003

Oh, C.-T., Moon, C., Choi, T. H., Kim, B. S., and Jang, J. (2013). Mycobacterium marinum infection in Drosophila melanogaster for antimycobacterial activity assessment. J. Antimicrob. Chemother. 68, 601-609. doi: 10.1093/jac/ dks 425

Oksanen, K. E., Halfpenny, N. J. A., Sherwood, E., Harjula, S.-K. E., Hammarén, M. M., Ahava, M. J., etal. (2013). An adult zebrafish model for preclinical tuberculosis vaccine development. Vaccine 31, 5202-5209. doi: 10.1016/.j.vaccine.2013.08.093
O'Quinn, A. L., Wiegand, E. M., and Jeddeloh, J. A. (2001). Burkholderia pseudomallei kills the nematode Caenorhabditis elegans using an endotoxin-mediated paralysis. Cell. Microbiol. 3, 381-393. doi: 10.1046/j.1462-5822.2001.00118.x

Orme, I. M. (2005a). Current progress in tuberculosis vaccine development. Vaccine 23, 2105-2108. doi: 10.1016/j.vaccine.2005.01.062

Orme, I. M. (2005b). Mouse and guinea pig models for testing new tuberculosis vaccines. Tuberculosis (Edinb.) 85, 13-17. doi: 10.1016/j.tube.2004.08.001

Page, D. M., Wittamer, V., Bertrand, J. Y., Lewis, K. L., Pratt, D. N., Delgado, N., et al. (2013). An evolutionarily conserved program of B-cell development and activation in zebrafish. Blood 122, el-e11. doi: 10.1182/blood-2012-12471029

Parikka, M., Hammaren, M. M., Harjula, S.-K. E., Halfpenny, N. J. A., Oksanen, K. E., Lahtinen, M. J., et al. (2012). Mycobacterium marinum causes a latent infection that can be reactivated by gamma irradiation in adult zebrafish. PLoS Pathog. 8:e1002944. doi: 10.1371/journal.ppat.1002944

Park, B., Iwase, T., and Liu, G. Y. (2011). Intranasal application of S. epidermidis prevents colonization by Methicillin-resistant Staphylococcus aureus in mice. PLoS ONE 6:e25880. doi: 10.1371/journal.pone.0025880

Phennicie, R. T., Sullivan, M. J., Singer, J. T., Yoder, J. A., and Kim, C. H. (2010). Specific resistance to Pseudomonas aeruginosa infection in zebrafish is mediated by the cystic fibrosis transmembrane conductance regulator. Infect. Immun. 78, 4542-4550. doi: 10.1128/IAI.00302-10

Phyu, S., Mustafa, T., Hofstad, T., Nilsen, R., Fosse, R., and Bjune, G. (1998). A mouse model for latent tuberculosis. Scand. J. Infect. Dis. 30, 59-68. doi: 10.1080/003655498750002321

Pier, G. B., Small, G. J., and Warren, H. B. (1990). Protection against mucoid Pseudomonas aeruginosa in rodent models of endobronchial infections. Science 249, 537-540. doi: 10.1126/science.2116663

Pilátová, M., and Dionne, M. S. (2012). Burkholderia thailandensis is virulent in Drosophila melanogaster. PLoS ONE 7:e49745. doi: 10.1371/journal.pone. 0049745

Polakowska, K., Lis, M. W., Helbin, W. M., Dubin, G., Dubin, A., Niedziolka, J. W., et al. (2012). The virulence of Staphylococcus aureus correlates with strain genotype in a chicken embryo model but not a nematode model. Microbes Infect. 14, 1352-1362. doi: 10.1016/j.micinf.2012.09.006

Polverino, E., Torres, A., Menendez, R., Cillóniz, C., Valles, J. M., Capelastegui, A., et al. (2013). Microbial aetiology of healthcare associated pneumonia in Spain: a prospective, multicentre, case-control study. Thorax 68, 1007-1014. doi: 10.1136/thoraxjnl-2013-203828

Pompilio, A., Pomponio, S., Crocetta, V., Gherardi, G., Verginelli, F., Fiscarelli, E., et al. (2011). Phenotypic and genotypic characterization of Stenotrophomonas maltophilia isolates from patients with cystic fibrosis: genome diversity, biofilm formation, and virulence. BMC Microbiol. 11:159. doi: 10.1186/1471-218011-159

Pozos, T. C., Ramakrishnan, L., and Ramakrishan, L. (2004). New models for the study of Mycobacterium-host interactions. Curr. Opin. Immunol. 16, 499-505. doi: 10.1016/i.coi.2004.05.011

Prajsnar, T. K., Cunliffe, V. T., Foster, S. J., and Renshaw, S. A. (2008). A novel vertebrate model of Staphylococcus aureus infection reveals phagocyte-dependent resistance of zebrafish to non-host specialized pathogens. Cell. Microbiol. 10, 2312-2325. doi: 10.1111/j.1462-5822.2008.01213.x

Proft, T., and Fraser, J. D. (2003). Bacterial superantigens. Clin. Exp. Immunol. 133, 299-306. doi: 10.1046/j.1365-2249.2003.02203.x

Prouty, M. G., Correa, N. E., Barker, L. P., Jagadeeswaran, P., and Klose, K. E. (2003). Zebrafish-Mycobacterium marinum model for mycobacterial pathogenesis. FEMS Microbiol. Lett. 225, 177-182. doi: 10.1016/S0378-1097(03) 00446-4

Purves, J., Cockayne, A., Moody, P. C. E., and Morrissey, J. A. (2010). Comparison of the regulation, metabolic functions, and roles in virulence of the glyceraldehyde3-phosphate dehydrogenase homologues gapA and gapB in Staphylococcus aureus. Infect. Immun. 78, 5223-5232. doi: 10.1128/IAI.00762-10

Rajagopalan, G., Sen, M. M., Singh, M., Murali, N. S., Nath, K. A., Iijima, K., et al. (2006). Intranasal exposure to staphylococcal enterotoxin B elicits an acute systemic inflammatory response. Shock 25, 647-656. doi: 10.1097/01.shk.0000209565.92445.7d

Ramachandran, S., Ruef, B., Pich, C., and Sprague, J. (2010). Exploring zebrafish genomic, functional and phenotypic data using ZFIN. Curr. Protoc. Bioinformatics Chap. 1, Unit 1.18. doi: 10.1002/0471250953.bi0118s31 
Ramakrishnan, L. (2013). Looking within the zebrafish to understand the tuberculous granuloma. Adv. Exp. Med. Biol. 783, 251-266. doi: 10.1007/978-1-46146111-1_13

Ramarao, N., Nielsen-Leroux, C., and Lereclus, D. (2012). The Insect Galleria mellonella as a powerful infection model to investigate bacterial pathogenesis. J. Vis. Exp. 70:e4392. doi: 10.3791/4392

Ratner, A. J., Bryan, R., Weber, A., Nguyen, S., Barnes, D., Pitt, A., et al. (2001). Cystic fibrosis pathogens activate $\mathrm{Ca}^{2+}$-dependent mitogen-activated protein kinase signaling pathways in airway epithelial cells. J. Biol. Chem. 276, 19267-19275. doi: 10.1074/jbc.M007703200

Rauta, P. R., Nayak, B., and Das, S. (2012). Immune system and immune responses in fish and their role in comparative immunity study: a model for higher organisms. Immunol. Lett. 148, 23-33. doi: 10.1016/j.imlet.2012.08.003

Rayner, C. F., Jackson, A. D., Rutman, A., Dewar, A., Mitchell, T. J., Andrew, P. W. et al. (1995). Interaction of pneumolysin-sufficient and -deficient isogenic variants of Streptococcus pneumoniae with human respiratory mucosa. Infect. Immun. 63, 442-447.

Redd, M. J., Kelly, G., Dunn, G., Way, M., and Martin, P. (2006). Imaging macrophage chemotaxis in vivo: studies of microtubule function in zebrafish wound inflammation. Cell Motil. Cytoskeleton 63, 415-422. doi: 10.1002/cm. 20133

Renshaw, S. A., Loynes, C. A., Elworthy, S., Ingham, P. W., and Whyte, M. K. B. (2007). Modeling inflammation in the zebrafish: how a fish can help us understand lung disease. Exp. Lung Res. 33, 549-554. doi: 10.1080/01902140701756778

Rodríguez-Rojas, A., Mena, A., Martín, S., Borrell, N., Oliver, A., and Blázquez, J. (2009). Inactivation of the hmgA gene of Pseudomonas aeruginosa leads to pyomelanin hyperproduction, stress resistance and increased persistence in chronic lung infection. Microbiology 155, 1050-1057. doi: 10.1099/mic.0.024745-0

Rombough, P. (2007). The functional ontogeny of the teleost gill: which comes first, gas or ion exchange? Comp. Biochem. Physiol. A Mol. Integr. Physiol. 148, 732-742. doi: 10.1016/j.cbpa.2007.03.007

Rounioja, S., Saralahti, A., Rantala, L., Parikka, M., Henriques-Normark, B., Silvennoinen, O., et al. (2012). Defense of zebrafish embryos against Streptococcus pneumoniae infection is dependent on the phagocytic activity of leukocytes. Dev. Comp. Immunol. 36, 342-348. doi: 10.1016/j.dci.2011.05.008

Russell, W. M. S. (1995). The development of the three Rs concept. Altern. Lab. Anim. 23, 298-304.

Russell, W., and Burch, R. (1959). The Principles of Humane Experimental Technique. London: Methuen.

Ruyra, A., Cano-Sarabia, M., García-Valtanen, P., Yero, D., Gibert, I., Mackenzie, S. A., et al. (2014). Targeting and stimulation of the zebrafish (Danio rerio) innate immune system with LPS/dsRNA-loaded nanoliposomes. Vaccine 32, 3955-3962. doi: 10.1016/j.vaccine.2014.05.010

Saini, D., Hopkins, G. W., Seay, S. A., Chen, C.-J., Perley, C. C., Click, E. M., et al. (2012). Ultra-low dose of Mycobacterium tuberculosis aerosol creates partial infection in mice. Tuberculosis (Edinb.) 92, 160-165. doi: 10.1016/j.tube.2011.11.007

Sapru, K., Stotland, P. K., and Stevenson, M. M. (1999). Quantitative and qualitative differences in bronchoalveolar inflammatory cells in Pseudomonas aeruginosa-resistant and -susceptible mice. Clin. Exp. Immunol. 115, 103-109. doi: 10.1046/j.1365-2249.1999.00762.x

Saralahti, A., Piippo, H., Parikka, M., Henriques-Normark, B., Rämet, M., and Rounioja, S. (2014). Adult zebrafish model for pneumococcal pathogenesis. Dev. Comp. Immunol. 42, 345-353. doi: 10.1016/j.dci.2013.09.009

Sawai, T., Tomono, K., Yanagihara, K., Yamamoto, Y., Kaku, M., Hirakata, Y., et al. (1997). Role of coagulase in a murine model of hematogenous pulmonary infection induced by intravenous injection of Staphylococcus aureus enmeshed in agar beads. Infect. Immun. 65, 466-471.

Schulenburg, H., and Ewbank, J. J. (2007). The genetics of pathogen avoidance in Caenorhabditis elegans. Mol. Microbiol. 66, 563-570. doi: 10.1111/j.13652958.2007.05946.x

Seidenfeld, J. J., Mullins, R. C. III, Fowler, S. R., and Johanson, W. G. Jr. (1986). Bacterial infection and acute lung injury in hamsters. Am. Rev. Respir. Dis. 134, $22-26$.

Shi, C., Shi, J., and Xu, Z. (2011). A review of murine models of latent tuberculosis infection. Scand. J. Infect. Dis. 43, 848-856. doi: 10.3109/00365548.2011. 603745

Shivers, R. P., Pagano, D. J., Kooistra, T., Richardson, C. E., Reddy, K. C., Whitney, J. K., et al. (2010). Phosphorylation of the conserved transcription factor ATF-7 by PMK-1 p38 MAPK regulates innate immunity in Caenorhabditis elegans. PLoS Genet. 6:e1000892. doi: 10.1371/journal.pgen.1000892

Sifri, C. D., Baresch-Bernal, A., Calderwood, S. B., and von Eiff, C. (2006). Virulence of Staphylococcus aureus small colony variants in the Caenorhabditis elegans infection model. Infect. Immun. 74, 1091-1096. doi: 10.1128/IAI.74.2.10911096.2006

Sifri, C. D., Begun, J., and Ausubel, F. M. (2005). The worm has turned - microbial virulence modeled in Caenorhabditis elegans. Trends Microbiol. 13, 119-127. doi: 10.1016/j.tim.2005.01.003

Sifri, C. D., Begun, J., Ausubel, F. M., and Calderwood, S. B. (2003). Caenorhabditis elegans as a model host for Staphylococcus aureus pathogenesis. Infect. Immun. 71, 2208-2217. doi: 10.1128/IAI.71.4.2208-2217.2003

Smith, M. P., Laws, T. R., Atkins, T. P., Oyston, P. C. F., de Pomerai, D. I., and Titball, R. W. (2002). A liquid-based method for the assessment of bacterial pathogenicity using the nematode Caenorhabditis elegans. FEMS Microbiol. Lett. 210, 181-185. doi: 10.1111/j.1574-6968.2002.tb11178.x

Sprynski, N., Valade, E., and Neulat-Ripoll, F. (2014). Galleria mellonella as an infection model for select agents. Methods Mol. Biol. 1197, 3-9. doi: 10.1007/9781-4939-1261-2_1

Srivastava, A., Casey, H., Johnson, N., Levy, O., and Malley, R. (2007). Recombinant bactericidal/permeability-increasing protein rBPI21 protects against pneumococcal disease. Infect. Immun. 75, 342-349. doi: 10.1128/IAI. 01089-06

Staczek, J., Gilleland, H. E. Jr., Gilleland, L. B., Harty, R. N., García-Sastre, A., Engelhardt, O. G., et al. (1998). A chimeric influenza virus expressing an epitope of outer membrane protein $\mathrm{F}$ of Pseudomonas aeruginosa affords protection against challenge with $P$. aeruginosa in a murine model of chronic pulmonary infection. Infect. Immun. 66, 3990-3994.

Starke, J. R., Edwards, M. S., Langston, C., and Baker, C. J. (1987). A mouse model of chronic pulmonary infection with Pseudomonas aeruginosa and Pseudomonas cepacia. Pediatr. Res. 22, 698-702. doi: 10.1203/00006450-19871200000017

Stevens, C. W. (1992). Alternatives to the use of mammals for pain research. Life Sci. 50, 901-912. doi: 10.1016/0024-3205(92)90167-N

Stevenson, M. M., Kondratieva, T. K., Apt, A. S., Tam, M. F., and Skamene, E. (1995). In vitro and in vivo $\mathrm{T}$ cell responses in mice during bronchopulmonary infection with mucoid Pseudomonas aeruginosa. Clin. Exp. Immunol. 99, 98-105. doi: 10.1111/j.1365-2249.1995.tb03478.x

Strähle, U., Scholz, S., Geisler, R., Greiner, P., Hollert, H., Rastegar, S., et al. (2012). Zebrafish embryos as an alternative to animal experiments-a commentary on the definition of the onset of protected life stages in animal welfare regulations. Reprod. Toxicol. 33, 128-132. doi: 10.1016/j.reprotox.2011.06.121

Stundick, M. V., Albrecht, M. T., Houchens, C. R., Smith, A. P., Dreier, T. M., and Larsen, J. C. (2013). Animal models for Francisella tularensis and Burkholderia species: scientific and regulatory gaps toward approval of antibiotics under the FDA animal rule. Vet. Pathol. 50, 877-892. doi: 10.1177/03009858134 86812

Sulston, J., and Hodgkin, J. (1988). "Methods," in The Nematode Caenorhabditis elegans, ed. W. B. Wood (New York, NY: Cold Spring Harbor Laboratory Press), 587-606.

Sunyer, J. O., Boshra, H., and Li, J. (2005). Evolution of anaphylatoxins, their diversity and novel roles in innate immunity: insights from the study of fish complement. Vet. Immunol. Immunopathol. 108, 77-89. doi: 10.1016/j.vetimm.2005.07.009

Swaim, L. E., Connolly, L. E., Volkman, H. E., Humbert, O., Born, D. E., and Ramakrishnan, L. (2006). Mycobacterium marinum infection of adult zebrafish causes caseating granulomatous tuberculosis and is moderated by adaptive immunity. Infect. Immun. 74, 6108-6117. doi: 10.1128/IAI.00887-06

Takaki, K., Davis, J. M., Winglee, K., and Ramakrishnan, L. (2013). Evaluation of the pathogenesis and treatment of Mycobacterium marinum infection in zebrafish. Nat. Protoc. 8, 1114-1124. doi: 10.1038/nprot.2013.068

Tam, M., Snipes, G. J., and Stevenson, M. M. (1999). Characterization of chronic bronchopulmonary Pseudomonas aeruginosa infection in resistant and susceptible inbred mouse strains. Am. J. Respir. Cell Mol. Biol. 20, 710-719. doi: 10.1165/ajrcmb.20.4.3223

Tan, M.-W. (2002). Identification of host and pathogen factors involved in virulence using Caenorhabditis elegans. Methods Enzymol. 358, 13-28. doi: 10.1016/S0076$6879(02) 58078-2$ 
Tan, M. W., and Ausubel, F. M. (2000). Caenorhabditis elegans: a model genetic host to study Pseudomonas aeruginosa pathogenesis. Curr. Opin. Microbiol. 3, 29-34. doi: 10.1016/S1369-5274(99)00047-8

Tan, M. W., Mahajan-Miklos, S., and Ausubel, F. M. (1999a). Killing of Caenorhabditis elegans by Pseudomonas aeruginosa used to model mammalian bacterial pathogenesis. Proc. Natl. Acad. Sci. U.S.A. 96, 715-720. doi: 10.1073/pnas.96.2.715

Tan, M. W., Rahme, L. G., Sternberg, J. A., Tompkins, R. G., and Ausubel, F. M. (1999b). Pseudomonas aeruginosa killing of Caenorhabditis elegans used to identify P. aeruginosa virulence factors. Proc. Natl. Acad. Sci. U.S.A. 96, 2408-2413. doi: 10.1073/pnas.96.5.2408

Teles, R., Wang, C. Y., and Stashenko, P. (1997). Increased susceptibility of RAG-2 SCID mice to dissemination of endodontic infections. Infect. Immun. 65, 37813787.

Terashima, T., Kanazawa, M., Sayama, K., Urano, T., Sakamaki, F., Nakamura, H., et al. (1995). Neutrophil-induced lung protection and injury are dependent on the amount of Pseudomonas aeruginosa administered via airways in guinea pigs. Am. J. Respir. Crit. Care Med. 152, 2150-2156. doi: 10.1164/ajrccm.152.6.8520789

Thomas, R., Hamat, R. A., and Neela, V. (2013). Stenotrophomonas maltophilia: pathogenesis model using Caenorhabditis elegans. J. Med. Microbiol. 62, $1777-$ 1779. doi: 10.1099/jmm.0.063230-0

Tobin, D. M., and Ramakrishnan, L. (2008). Comparative pathogenesis of Mycobacterium marinum and Mycobacterium tuberculosis. Cell. Microbiol. 10, 1027-1039. doi: 10.1111/j.1462-5822.2008.01133.x

TranVan Nhieu, G., Clair, C., Grompone, G., and Sansonetti, P. (2004). Calcium signalling during cell interactions with bacterial pathogens. Biol. Cell 96, 93-101. doi: 10.1016/j.biolcel.2003.10.006

van der Sar, A. M., Abdallah, A. M., Sparrius, M., Reinders, E., VandenbrouckeGrauls, C. M. J. E., and Bitter, W. (2004a). Mycobacterium marinum strains can be divided into two distinct types based on genetic diversity and virulence. Infect. Immun. 72, 6306-6312. doi: 10.1128/IAI.72.11.6306-6312.2004

van der Sar, A. M., Appelmelk, B. J., Vandenbroucke-Grauls, C. M. J. E., and Bitter, W. (2004b). A star with stripes: zebrafish as an infection model. Trends Microbiol. 12, 451-457. doi: 10.1016/j.tim.2004.08.001

van Heeckeren, A. M., and Schluchter, M. D. (2002). Murine models of chronic Pseudomonas aeruginosa lung infection. Lab. Anim. 36, 291-312. doi $10.1258 / 002367702320162405$

Vilaplana, C., and Cardona, P.-J. (2014). The lack of a big picture in tuberculosis: the clinical point of view, the problems of experimental modeling and immunomodulation. The factors we should consider when designing novel treatment strategies. Front. Microbiol. 5:55. doi: 10.3389/fmicb.2014.00055

Volkman, H. E., Clay, H., Beery, D., Chang, J. C. W., Sherman, D. R., and Ramakrishnan, L. (2004). Tuberculous granuloma formation is enhanced by a mycobacterium virulence determinant. PLoS Biol. 2:e367. doi: 10.1371/journal.pbio.0020367

Volkman, H. E., Pozos, T. C., Zheng, J., Davis, J. M., Rawls, J. F., and Ramakrishnan, L. (2010). Tuberculous granuloma induction via interaction of a bacterial secreted protein with host epithelium. Science 327, 466-469. doi: 10.1126/science.1179663

Wand, M. E., Müller, C. M., Titball, R. W., and Michell, S. L. (2011). Macrophage and Galleria mellonella infection models reflect the virulence of naturally occurring isolates of B. pseudomallei, B. thailandensis and B. oklahomensis. BMC Microbiol. 11:11. doi: 10.1186/1471-2180-11-11

Warawa, J. M. (2010). Evaluation of surrogate animal models of melioidosis. Front. Microbiol. 1:141. doi: 10.3389/fmicb.2010.00141

Waters, V. J., Gómez, M. I., Soong, G., Amin, S., Ernst, R. K., and Prince, A. (2007) Immunostimulatory properties of the emerging pathogen Stenotrophomonas maltophilia. Infect. Immun. 75, 1698-1703. doi: 10.1128/IAI.01469-06
Watkins-Chow, D. E., and Pavan, W. J. (2008). Genomic copy number and expression variation within the C57BL/6J inbred mouse strain. Genome Res. 18, 60-66. doi: 10.1101/gr.6927808

Wilmott, R. W., Kitzmiller, J. A., Szabó, C., Southan, G. J., and Salzman, A. L. (2000). Mercaptoethylguanidine inhibits the inflammatory response in a murine model of chronic infection with Pseudomonas aeruginosa. J. Pharmacol. Exp. Ther. 292, $88-95$.

Woodhead, M. (2013). Pneumonia classification and healthcare-associated pneumonia: a new avenue or just a cul-de-sac? Thorax 68, 985-986. doi: 10.1136/thoraxjnl-2013-204060

Wu, K., Conly, J., McClure, J.-A., Elsayed, S., Louie, T., and Zhang, K. (2010). Caenorhabditis elegans as a host model for community-associated methicillinresistant Staphylococcus aureus. Clin. Microbiol. Infect. 16, 245-254. doi: 10.1111/j.1469-0691.2009.02765.x

Wu, K., Conly, J., Surette, M., Sibley, C., Elsayed, S., and Zhang, K. (2012). Assessment of virulence diversity of methicillin-resistant Staphylococcus aureus strains with a Drosophila melanogaster infection model. BMC Microbiol. 12:274. doi: $10.1186 / 1471-2180-12-274$

Wu, K., Zhang, K., McClure, J., Zhang, J., Schrenzel, J., Francois, P., et al. (2013). A correlative analysis of epidemiologic and molecular characteristics of methicillinresistant Staphylococcus aureus clones from diverse geographic locations with virulence measured by a Caenorhabditis elegans host model. Eur. J. Clin. Microbiol. Infect. Dis. 32, 33-42. doi: 10.1007/s10096-012-1711-x

Xu, J., Du, L., and Wen, Z. (2012). Myelopoiesis during zebrafish early development. J. Genet. Genomics 39, 435-442. doi: 10.1016/j.jgg.2012.06.005

Young, D. (2009). Animal models of tuberculosis. Eur. J. Immunol. 39, 2011-2014. doi: 10.1002/eji.200939542

Yuen, G. J., and Ausubel, F. M. (2014). Enterococcus infection biology: lessons from invertebrate host models. J. Microbiol. 52, 200-210. doi: 10.1007/s12275-0144011-6

Zak, O., and O'Reilly, T. (1993). Animal infection models and ethics the perfect infection model. J. Antimicrob. Chemother. 31, 193-205. doi: 10.1093/jac/31.suppl_D.193

Zhang, T., Li, S.-Y., Williams, K. N., Andries, K., and Nuermberger, E. L. (2011). Short-course chemotherapy with TMC207 and rifapentine in a murine model of latent tuberculosis infection. Am. J. Respir. Crit. Care Med. 184, 732-737. doi: 10.1164/rccm.201103-0397OC

Conflict of Interest Statement: The authors declare that the research was conducted in the absence of any commercial or financial relationships that could be construed as a potential conflict of interest.

Received: 24 November 2014; accepted: 12 January 2015; published online: 04 February 2015.

Citation: López Hernández Y, Yero D, Pinos-Rodríguez JM and Gibert I (2015) Animals devoid of pulmonary system as infection models in the study of lung bacterial pathogens. Front. Microbiol. 6:38. doi: 10.3389/fmicb.2015.00038

This article was submitted to Infectious Diseases, a section of the journal Frontiers in Microbiology.

Copyright (c) 2015 López Hernández, Yero, Pinos-Rodríguez and Gibert. This is an open-access article distributed under the terms of the Creative Commons Attribution License (CC BY). The use, distribution or reproduction in other forums is permitted, provided the original author(s) or licensor are credited and that the original publication in this journal is cited, in accordance with accepted academic practice. No use, distribution or reproduction is permitted which does not comply with these terms. 